\title{
Satellite Inferred Surface Albedo Over Northwestern Africa
}

\author{
By \\ A.A. Rockwood and S.K. Cox \\ Department of Atmospheric Science \\ Colorado State University \\ Fort Collins, Colorado
}

Research supported by the Global Atmospheric Research Program, NSF and the GATE

Project Office, NOAA under grants OCD74-21678 and OCD72-01681 A03.

November 1976
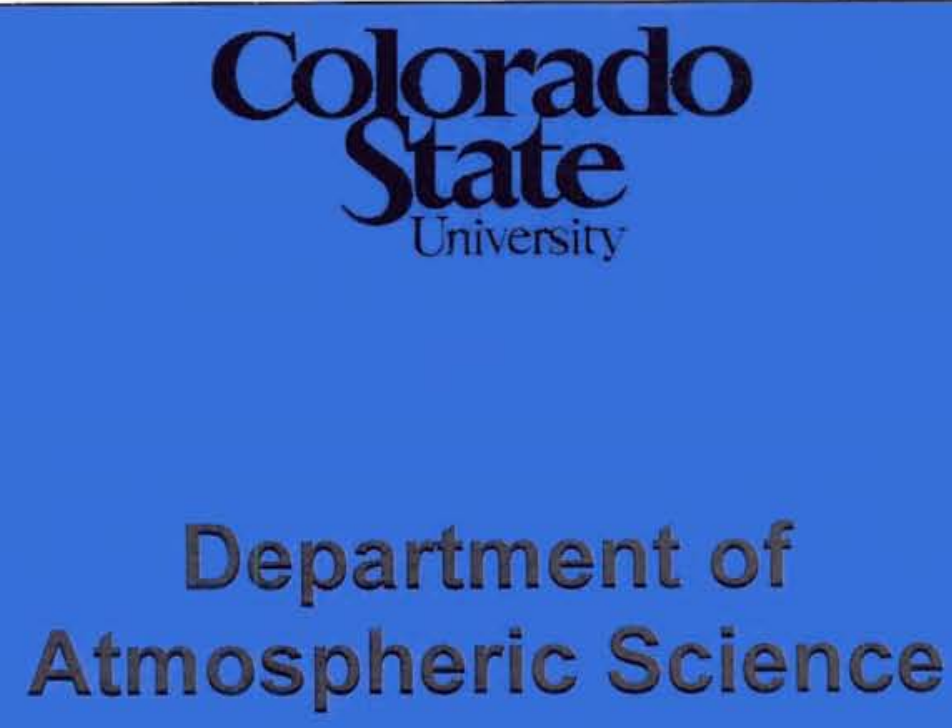

Paper No. 265 
SATELLITE INFERRED SURFACE ALBEDO

OVER NORTHWESTERN AFRICA

by

Anthony A. Rockwood

and

Stephen K. Cox

Research Report supported by The GTobal Atmospheric Research Program, National Science Foundation and the GATE Project Office, NOAA under grants $O C D-74-21678$ and $O C D-72-01681 A 03$

Department of Atmospheric Science

Colorado State University

Fort Collins, Colorado 80523

November 1976

Atmospheric Science Paper No. 262 


\section{ABSTRACT \\ SATELLITE INFERRED ALBEDO OVER NORTHWESTERN AFRICA}

A technique is developed that allows the albedo of the earth's surface to be inferred from the SMS-1 satellite measurements of the earth-atmosphere system brightness. The technique uses simultaneous satellite and aircraft measurements from the SMS- 1 and the NCAR Sabreliner during the GATE in 1974. Albedo values measured by the aircraft ranged from .50 over the Sahara Desert to .07 over wet tropical rain forests. The albedos inferred through the employment of the technique are used to study the changes in the surface characteristics between july and September, 1974. Significant changes in the gradient of albedo and areal extent of various vegetation patterns are observed. The albedo values generated through this technique should be incorporated into the numerical and analytic models of the atmosphere that have recently been used to study local precipitation trends. 


\section{ACKNOWLEDGEMENTS}

I would like to extend thanks to Ms. Sandra Wunch and Ms. Susan Kuehi for typing the manuscript, and to Ms. Pauline Martin for coordinating the drafting. Special thanks are due to Ms. Charline Polifka for her expert programming assistance. I also thank Mr. Eric A. Smith for his dedication to the navigation of the SMS-1 satellite data.

This research has been supported by the Giobal Atmospheric Research Program, the National Science Foundation, and the GATE Project Office, NOAA, under Grants OCD 72-01681 AO3 and OCD 74-21678. Acknow1edgement is also made to the Flight Facility and Computing Facility of the National Center for Atmospheric Research, sponsored by the National Science Foundation. 
ABSTRACT

ACKNOWLEDGEMENTS

TABLE OF CONTENTS

LIST OF TABLES

vii

LIST OF FIGURES

ix

1.0 INTRODUCTION

2.0 DATA COLLECTION AND ANALYSIS 5

2.1 Aircraft Measurement System 5

2.2 Data Reduction and Correction 6

2.21 Estimate of the Direct Component of Measured 10 Irradiance

2.3 CSAS Mission Abstracts

2.4 Aibedo Data Anaiysis

3.0 ALBEDO INFERENCE TECHNIQUE

3.1 Radiation Budget Equation

3.2 Remote Sensing by Satelitite

3.3 Estimates of Atmosheric Absorptivity

3.4 Brightness vs. PSYS Algorithm

3.5 Sensitivity of $\alpha_{S F C}$ to the Estimates of $a_{A T}$

3.6 Surface Classification System

3.7 Summary of the Albedo Inference Technique

4.0 APPLICATION OF INFERENCE TECHNIQUE

4.1 Limitation of the Technique

4.2 Albedo Map of the CSAS Region

4.3 Examination of the Seasonal Variation of Surface Albedo 39 


\section{TABLE OF CONTENTS - Continued}

PAGE

4.4 Discussion of the Results 42

5.0 CONCLUSIONS 51

REFERENCES 55

APPENDIX 57 


\section{LIST OF TABLES}

TABLE

1 Empirical estimates of the direct percent of the total sky irradiance in a turbid atmosphere (Carlson, 1975).

2 Theoretical calculation of the direct percent of the total sky irradiance in a turbid atmosphere. Constructed from Robinson, 1966, using $P=1000 \mathrm{mb}$, precipitabie water $=3.7 \mathrm{~cm}$, and turbidity factor $=.04$ (dusty).

3 Measured irradiances during CSAS-147, September 4, 1974, 1130 LST. A11 means and standard deviations (o) are in $\mathrm{Wm}^{-2}$. H Ht is a 1200 LST calculation of the mean solar constant $\left(1380 \mathrm{Wm}^{-2}\right)$ corrected for sun-earth distance variation.

4 Brightness count (B) and the bulk radiative properties of the surface and atmosphere (Eq. 20) for the CSAS region on SEptember 4, 1974 at $1200 Z$. $H_{1} \uparrow=$ PSYS $1366 \mathrm{Vm}^{-2}$.

5 Percentage error in a SFe calculations due to an over or under estimate of a for three different transmissivity possibilities.

6 Surface C?assification System.

7 A comparison of the expected versus the observed

decrease in brightness count over the CSAS $\left(17.5^{\circ} \mathrm{N}\right)$ on July 2, 1974. The expected decrease is based on the assumption that the voltage output for the respective brightness values is a function of the cosine of the solar zenith angle.

8 Summary of the seasonal change in surface albedo (asfc) along $10^{\circ} \mathrm{W}$ longitude.

9 Percentage of the total area attributable to each surface class.

A1 $20 \mathrm{~nm}$ averages for CSAS-243. A11 irradiance means and standard deviations are $\mathrm{Wm}^{-2}$. Time and location are for the midpoint of the $20 \mathrm{~nm}$ segments.

A2 $20 \mathrm{~nm}$ averages for CSAS-247. Al1 irradiance means and standard deviations are $\mathrm{Wm}-2$. Time and location are for the midpoint of the $20 \mathrm{~nm}$ segments. 


\section{LIST OF TABLES - Continued}

$\underline{\text { TABLE }}$

PAGE

A3 $20 \mathrm{~nm}$ averages for CSAS-248. A17 irradiance means

and standard deviations are $\mathrm{Wm}^{-2}$. Time and location are for the midpoint of the $20 \mathrm{~nm}$ segments.

A4 $20 \mathrm{~nm}$ averages for CSAS-252. All irradiance means and standard deviations are $\mathrm{Wm}^{-2}$. Time and location are for the midpoint of the $20 \mathrm{~nm}$ segments. 
Figure 1. Continental Surface Aibedo Survey (CSAS) area. The low-ievel fiight tracks are designated by mission number in the inset.

Figure 2. Diagram of the angles and planes involved in the correction of the solar irradiance on an inciined plane. (Adapted from Sellers, 1965.)

Figure 3. A one-layer atmospheric model bounded by a partially reflecting homogeneous surface.

Figure 4. Scatter diagram of the empirical relationship

between mean surface albedo (OSFC) and mean SMS-1

brightness count (B) over the CSAS region on

Septenber 4, 1974 at 12002 . The solid line is

the best fit using a second order polynomial. The

dashed line is a theoretical relationship

resulting from a linear relationship between ${ }^{\circ}$ SYS and $B$.

Figure 5. Relationship between reflectivity of the earth-

a tmosphere system (osys) and mean SMS-1 brightness

count (B) over the CS̃AS region on September 4,

1974 at 12002 . The solid line is calculated using

the values of the three abscissas in Eq. 20. The

dashed line is a theoretical estimate of the

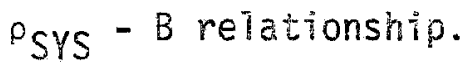

Figure 6. Surface Classification System superimposed on the

PSYS VS. aSFC curve of Figure 4 . The physical

description of each class is given in Sec. 3.6.

Figure 7. Flow diagram of the albedo inference technique.

Figure 8. Mean $1000 \mathrm{mb}$ specific humidity during an 11 year

period for West Africa, $13^{\circ} \mathrm{N}$. (Aspliden and Adefolalu, 1976.)

Figure 9. Kean $1000 \mathrm{mb}$ specific humidity during an 11 year

period for west Africa, $5^{\circ} \mathrm{N}$. (Aspliden and Adefola7u, 1976.)

Figure 10. Surface albedo analysis of the CSAS region at $1200 z$ on September 4, 1974 showing flight tracks designated by Julian day number. The contours correspond to the Surface Classification System.

Figure 11. Surface albedo analysis for $1200 z$ on July 2, 1974.

Figure 12. Visible photograph from SMS-1 satellite at $1200 Z$ on JuTy $2,1974$. 
Figure 13. Surface albedo analysis for 12002 on August 10, 1974.

Figure 14. Visible photograph from SMS-1 sate17ite at $1200 Z$ cn August 10, 1974.

Figure 15. Surface albedo analysis for 12002 on September 20,1974 .

Figure 16. Visible photograph from SMS-1 satellite at 12002 on September 20, 1974. 


\subsection{INTRODUCTION}

In recent years investigators have suggested the importance of the brcadband shortwave surface albedo in forcing atmospheric circulations. Cherney (1975) and Budyko (1969) have shown the surface characteristics of a region to be one of the most variable of an area's radiation budget components. Changes in surface cheracteristics have been thought to intiate changes in local circulations, thus altering existing weather patterns.

The northwestern region of the African continent provides one of the world's best natura? laboratorjes for the study of surface albedo changes. It is also an area whose economy has been seriously affected by recent changes in the precipitation patterns. Within this region tropical rain forests with annual precipitation amounts in excess of $200 \mathrm{~cm}$ are found adjacent to the Sahara Desert with annual precipita:ion amounts less than $10 \mathrm{~cm}$ (Sellers, 1965). Between these two extremes lies the sarel region which periodically suffers the consequences when the desert encroaches from the north. Associated with these precipitation amounis are distinct vegetation types ranging from canopied jungles and swamp to sparse scrub, and soil types including baked clay and brilitant white sand. These surface characteristics change more dramatically within a limited area than on any other part of the earth. The surface albedo, a direct function of these surface types: is consequentiy found to be highly variable. Raschke et al. (7973) present satellite observed reflected solar radiation measurements over this area. However, these data represent planetary albedo which include the effect of the atmosphere. 
Until recently, surface albedo values used in radiation budget studies of this area have been estimates based on measurements from other similar regions. With the increasing awareness of the importance of accurate surface measurements, a set of four aircraft missions was assigned to stucy the probiem as part of the Radiation Subprogram (RSP) of the Giobal Atmospheric Research Program (GARP) Atlantic Tropical Experiment (GATE) during the summer of 1974. The Continental Surface Albedo Survey (CSAS) had as its primary objective to make low-level (150 $\mathrm{m}$ above ground leve1, $A G L)$ aircraft fights over terrain ranging from sand to jungle and to record both the incident ( $\mathrm{H}_{\mathrm{SFC}}$ ) and reflected $\left(\mathrm{H}_{\mathrm{SFC}}\right)$ broadband $(.285 \mu-2.8 \mu)$ shortwave irradiances. The four flights were carried out under synoptic conditions ranging from clear sky to unfform trade cumitus to solid stratus overcast. Figure 1 shows the continental portion of the GATE region, and the inset shows the area studied in the CSAS. The four flight tracks are indicated by flight number (SuTian Day number).

A secondary objective of the CSAS was the measurement of both the incident $\left(H_{\eta} \psi\right)$ end reflected $\left(H_{1} \uparrow\right)$ broadband shortwave irradiance at an altitude of $12.5 \mathrm{~km}$. When the $\mathrm{H}_{7}$ \& values are compared with the present day estimates of the solar constant, they provide an empirica? basis for a statement of the accuracy of the irradiance measurement system. The $H_{7} \uparrow$ measurements allow for a calculation of the local earthatmosphere reflectivity.

The CSAS would be of diminished value because of the relatively sinall area sampled unless the measured albedos could be used to infer the albedo of other areas. With this in mind, this research attempts to deduce a relationship between the visible system brightness 


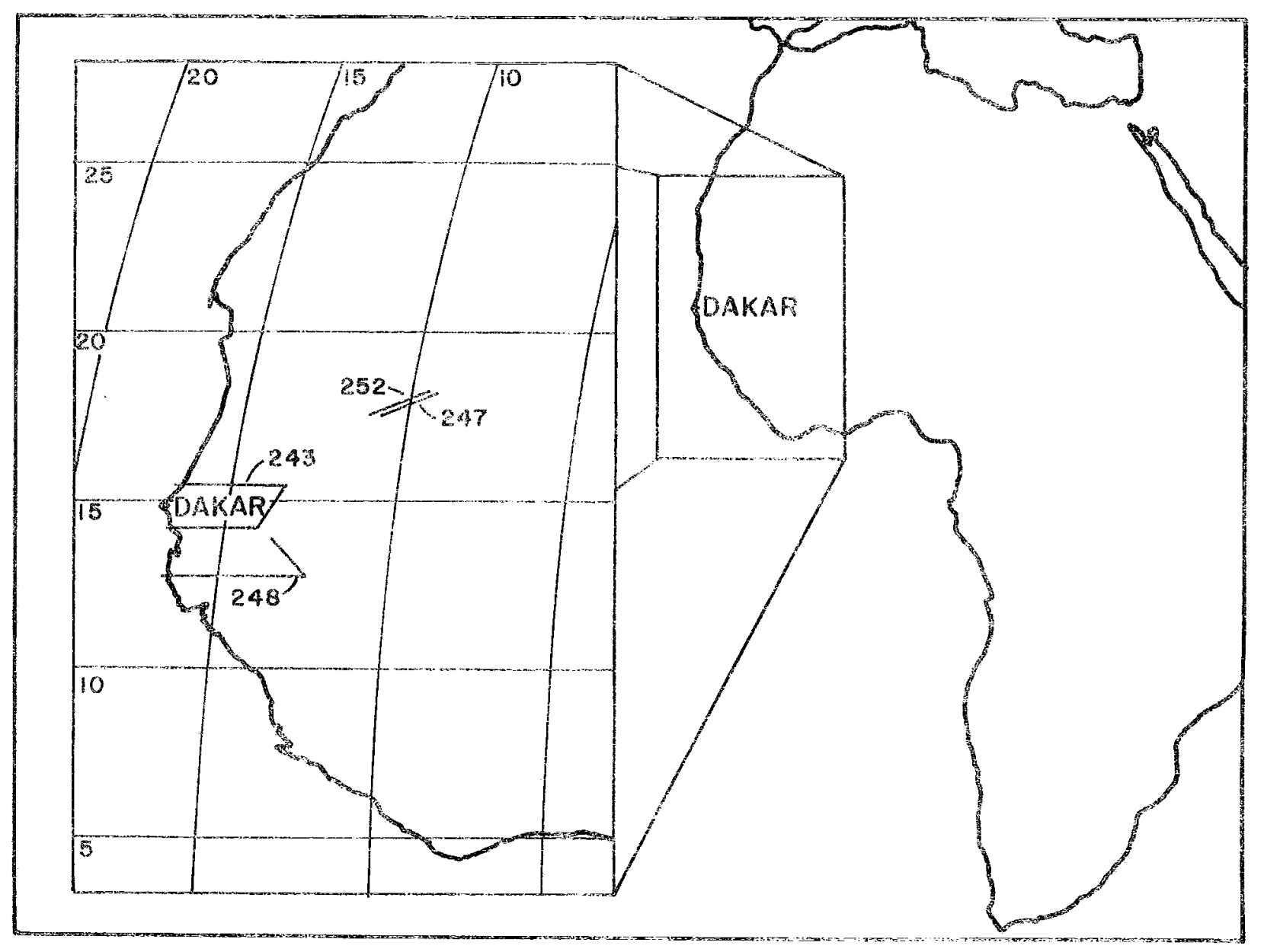

Figure 1. Continental Surface ATbedo Survey (CSAS) area. The low-leve1 flight tracks are designated by mission number in the inset. 
$(.55 \mu-.75 \mu)$ observed by the SMS-1 satellite (launched just prior to the GATE and the CSAS) and the measured surface albedo. It is known that an empirical relationship does indeed exist, since one is abie to observe surface albedo differences simply by looking at a satellite photograph. But a more specific, quantitative relationship that may then be applied to a much larger area is the goal of this study. This relationship would be a very useful tool if it may be used to infer surface albedos over areas where there are no direct surface measurements.

Finally, the visible brightness relationship is used to explore the possibility that there may be a measurable variation to the surface albedo over nortinwestern Africa on a seasonal scaie. Surface albedo Tluctuations hav? been hypothesized (Charney, 1975; Budyko, 1969; and Otterman, 1974) to occur on a time scaie of years and even decades die to such factors as improper land management including over-grazing by livestock. These mechanisms are indeed real, but there may be an equally important seasonal variation that has been overlooked. It is hoped that this technique may be used to show just such a variation. 


\subsection{DATA COLLECTION AND ANALYSIS}

\subsection{Aircraft Measurement System}

The system for measuring the shortwave irradiance used two Eppley Precision Pyranometers mounted on the exterior of the NCAR (National Center for Atmospheric Research) Sabreliner. The upward facing instrument was mounted on the aircraft fuselage, while the downward facing instrument was mounted beneath the port wing. Precautions were taken to assure a paral?ei mounting of these instruments with the lateral and Tongitudina? axes of the aircraft. The Eppley Precision Pyranometers are hemispheric radioneters measuring within a spectral range of $.285-2.8$ wh. The millivolt signals from the pyranometers were relayed to interior-mounted ampiffiers (Acromag, model 317 , By-s thermocouple) where they were amplified and recorded on magnetic tape by the aircraft data logging system. Each instrument measured the irradiance four times per second, while the data available for analysis were reduced to one second mean values. A complete description of 211 of the Sabreliner radiation instrumentation during GATE may be found in ATbrecht and Cox, 1976.

For the purpose of measuring the shortwave surface albedo, all flights were conducted at a mean altitude of $150 \mathrm{~m}$. AGL (above ground leve1) and at a mean true airspeed of $125 \mathrm{~ms}^{-1}$. Level flight in the Sabreliner under the existing loading conditions required an aircratt angle of atcack of approximately $3.7^{\circ}$. Aircraft indicated airspead, exterior total air temperature, static pressure, true heading. and angle of attack were all recorded once per second by the dato logging system. 
In addition to the irradiance measurement system, a. 16 mm movie camera was mounted on board the Sabreliner, and a frame was taken once every eight seconds to record the surface and sky conditions during the CSAS missions. These films, along with the entries from the airborne mission scientists's logbooks, were used in an analysis of the correlation between the irradiance data and the various surface conditions.

\subsection{Data Reduction and Correction}

The pyranometers, their respective amplifiers, and the data logging system were calibrated together to determine the exact relationship between the input signal and the recorded data. This relationship was found to be linear and did not vary significantly during the course of the CSAS fie?d experiment (A7brecht and Cox, i976). The relitionship was applied to the recorded data to generate the first order irradiance values.

Because of the nature of the hemispheric pyranometers (Robinson, 1966), several other temperature and geometry reiated correction factors were apolied to the first order irradiance values.

With regard to the temperature correction factor, the exterior mounted pyranometers were subjected to a total air temperature* range of $40^{\circ} \mathrm{C}$ to $-40^{\circ} \mathrm{C}$ during CSAS missions. The Eppley Precision Pyranometers do have a temperature compensating circuitry, however, a further tempenature calibration was considered necessary for this large of a temperature range. The result of this calibration

* The total air temperature is the ambient air temperature plus the dynamic heating due to the air motion. 
procedure, conducted at Colorado State University, was to increase the first order irradiance values by .01 to 3 percent (Albrecht and Cox, 1976). A11 further irradiance values used in this study were temperature corrected.

A geometry correction factor was used to correct the downward irradiance values for the fact that the aircraft flew in a plane other than the horizontal plane of the earth (see Fig. 2). Since the pyranometers were carefuliy mounted parallel to the lateral and longitudinal axes of the aircraft (Sec. 2.1), the plane of the pyranometers was a function of oniy the aircraft angle of attack and the aircraft true heading. The roll of the aircraft was considered negligible since it would integrate to near zero with time. The magnitude of the correction factor was greatest for large solar zenith angles and when a large portion of the total sky irradiance was direct rather than diffuse. For low solar zenith angles, between the hours of $10 \mathrm{a} . \mathrm{m}$. and 2 p.m. . LST, and when most of the measured irradiance was diffuse, such as for the downward facing pyranometer and for the upward facing pyranometer under uniform clcudiness, the geometry correction factor became insignificant. For the purpose of this research, all data obtained by the upward facing pyranometer were geometry corrected regardless of how small the solar zenith angle. Details of the geometry correction procedure are given below.

Symbols defined

$\mathrm{H}_{4} \mathrm{H}$ - irradiance on a horizontal plane

H* $\psi_{0}$ - irradiance on a plane perpendicular to the direct solar beam 


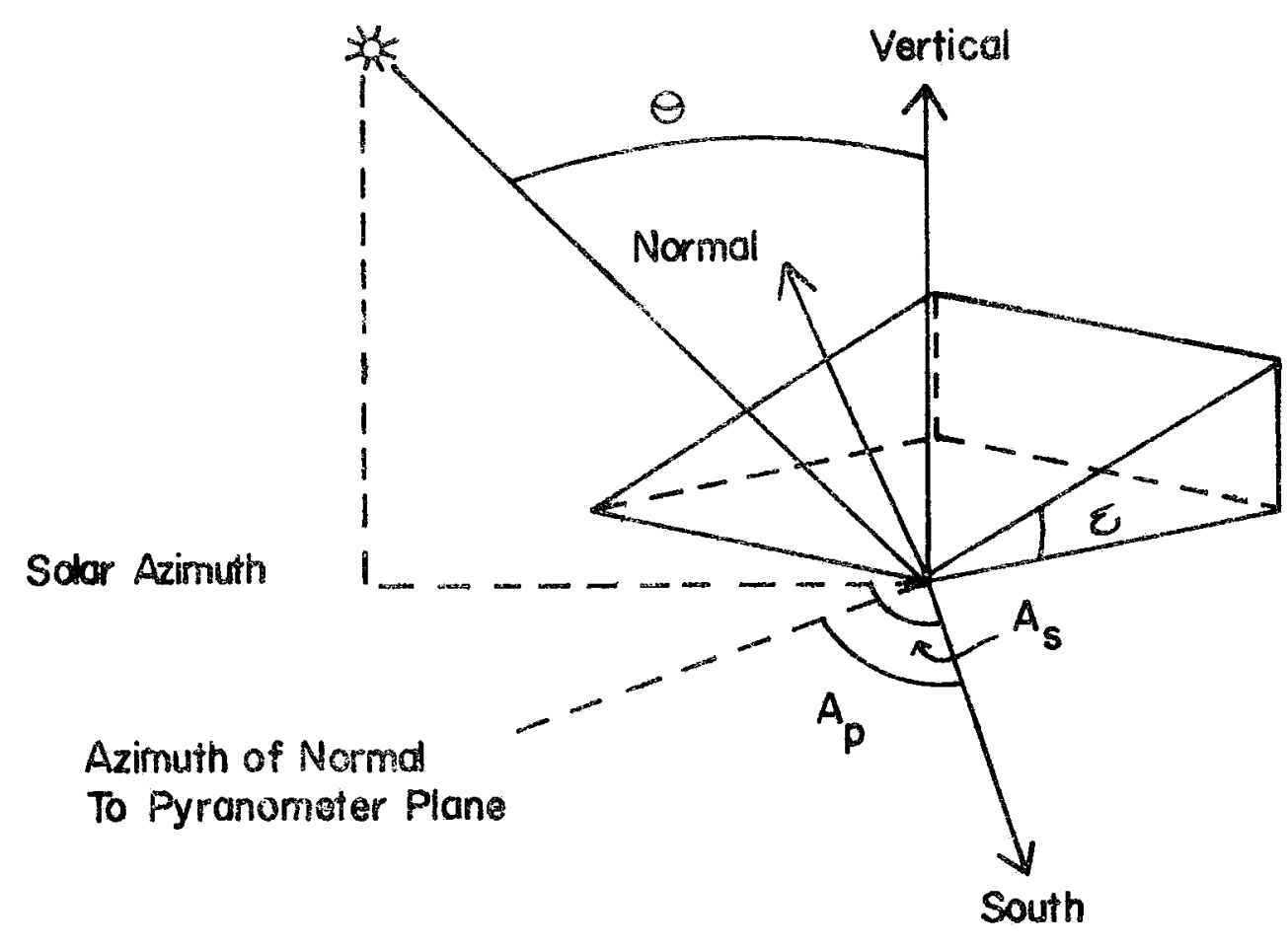

Figure 2. Diagram of the angles and planes involved in the correction of the solar irradiance on an inclined plane. (Adapted from sellers. 1965.) 


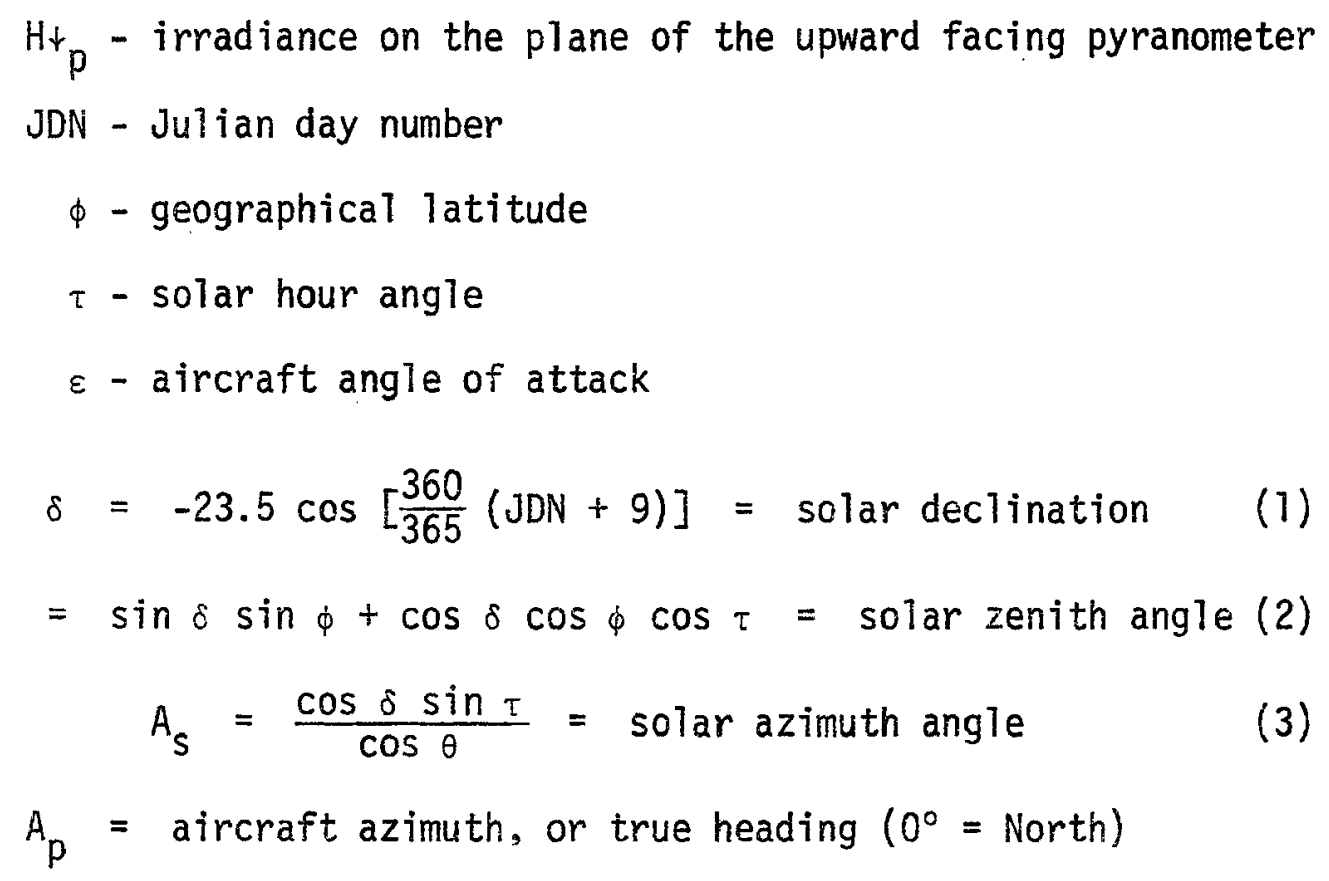

The following relationships exist between these definitions and equations. Derivations of the equations may be found in Robinson, 1966 .

$$
\begin{aligned}
{ }^{H \psi_{H}} & =H_{0} \cos \theta \\
H \psi_{0} & =\frac{H \psi_{p}}{\cos \beta} \\
\cos \beta=\cos \varepsilon \cos \theta & -\sin \varepsilon \sin \theta \cos \left(A_{s}-A_{p}\right)
\end{aligned}
$$

Substituting Eqs. (5) and (6) into Eq. (4):

$$
H \downarrow_{H}=\frac{H \psi_{p} \cos \theta}{\cos \varepsilon \cos \theta-\sin \varepsilon \sin \theta \cos \left(A_{s}-A_{p}\right)}
$$

The correction factor $\left(\frac{\cos \theta}{\cos \beta}\right)$ is applied to only the direct component of the incident irradiance since the diffuse component need not be geometry corrected. Thus, in the data correction procedure, Eq. (7) becomes

$$
H_{\psi_{H}}=H_{\downarrow_{P}} \text { (diffuse) }+H_{\psi_{P}} \text { (direct) }\left(\frac{\cos \theta}{\cos \beta}\right)
$$

where

$$
H_{\mathrm{t}}(\text { total })=H_{\mathrm{t}}(\text { diffuse })+H_{\mathrm{t}}(\text { direct }) .
$$


2.21 Estimate of the Direct Component of Measured Irradiance

Equation 8 requires specification of the magnitude of the direct component of the incident solar irradiance during the CSAS experiment. Using irradiance values observed by Carlson (1975) on the island of Sal, Cape Verde during the Cape Verde solar radiation program of the GATE, Table $T$ was constructed from the mean values of the cloud-free days.

\begin{tabular}{ccc}
$\begin{array}{c}\text { HorizontaT } \\
\text { Visibility }(\mathrm{km})\end{array}$ & \multicolumn{2}{c}{ Time (LST) } \\
\hline 6 & $52 \%$ & $38 \%$ \\
10 & $57 \%$ & $50 \%$ \\
16 & $64 \%$ & $62 \%$ \\
$>16$ & $67 \%$ & $58 \%$
\end{tabular}

Table 1. Empirical estimates of the direct percent of the total sky irradiance in a turbid atmosphere (Carlson, 1975).

From Table 1 it may be seen that the direct percent of the total sky irradiance on a horizontal surface increases with greater horizontal visibility and with decreasing solar zenith angles. Horizontal visibility may be thought of as an empirical measure of atmospheric turbidity.

Robinson (1966) has made similar theoretical estimates of the components of the total sky irradiance as a function of atmospheric turbidity, water vapor content, and solar zenith angle. Table 2 was constructed by setting these parameters to match those on Sal during the GATE. 


\begin{tabular}{cc}
$\begin{array}{c}\text { Solar Zenith } \\
\text { Angle }\end{array}$ & $\begin{array}{l}\text { Direct Percent } \\
\text { of Total }\end{array}$ \\
\hline $0^{\circ}$ & 66 \\
$10^{\circ}$ & 66 \\
$20^{\circ}$ & 66 \\
$30^{\circ}$ & 66 \\
$40^{\circ}$ & 66 \\
$50^{\circ}$ & 67 \\
$60^{\circ}$ & 67 \\
$70^{\circ}$ & 65 \\
$80^{\circ}$ & 61
\end{tabular}

Table 2. Theoretical calculation of the direct percent of the total sky irradiance in a turbid atmosphere. Constructed from Robinson, 1966 , using $P=1000 \mathrm{mb}$, precipitabie water $=3.7 \mathrm{~cm}$, and turbidity factor $=$ .04 (dusty).

Since the empirical estimates and theoretical calculations are in close agreement for the times and atmospheric conditions most closely matching those of the CSAS missions, a value of 66 percent for the direct percent of the total sky irradiance was used in the geometry correction. Thus, Eq. 8 becomes

$$
H_{v_{H}}=.34 H_{t_{p}}+.66 H_{t_{p}}\left(\frac{\cos \theta}{\cos \beta}\right)
$$

The irradiances measured by the downward facing pyranometer were assumed to be totally diffuse, thus, no geometry correction was asplied to these data.

\section{L CSAS Mission Abstracts}

The following abstracts are intended to provide the reader with a brief overview of the dates, times, and locations of the individual missions. More descriptive summaries of the mission objectives, mateorological conditions, and the preliminary results may be found in the Appendix. 
CSAS -243

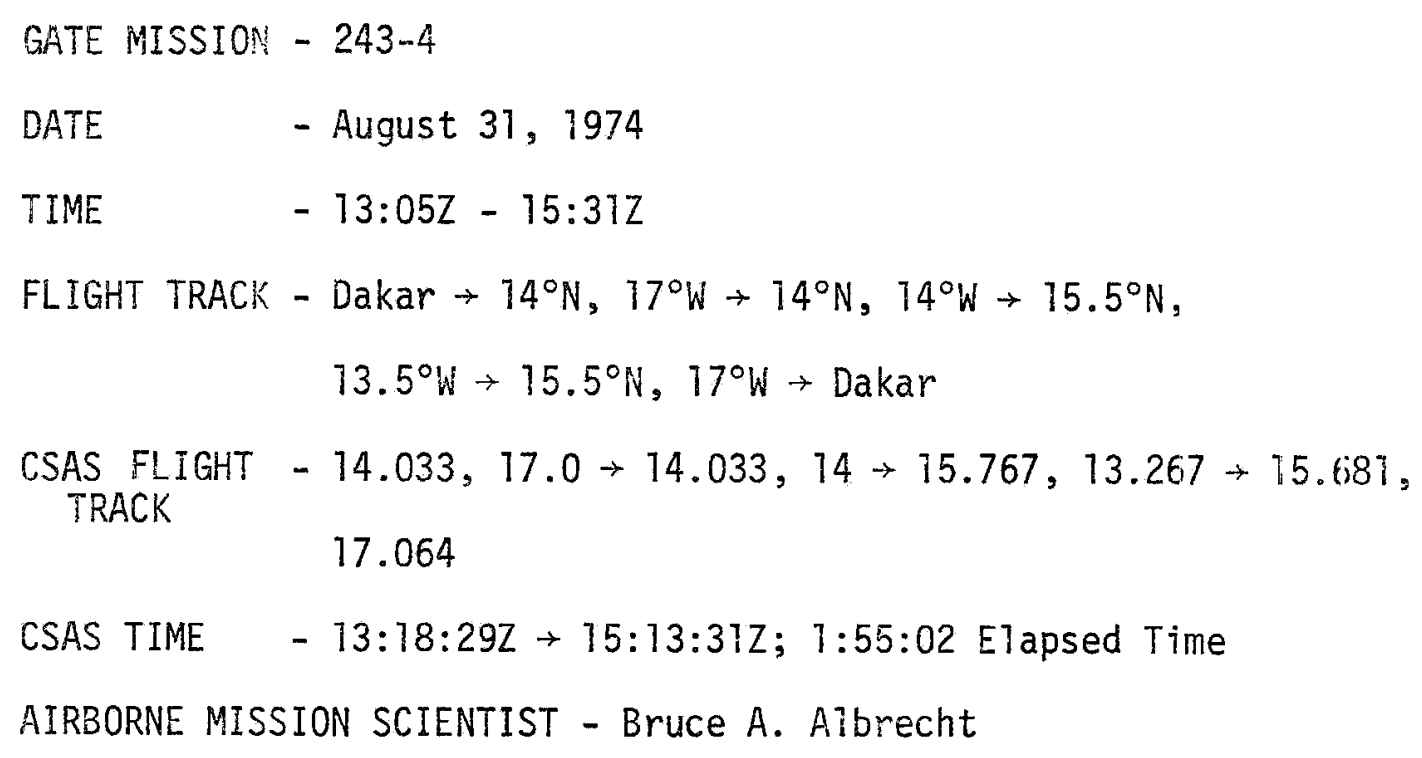

\section{CSAS -247}

GATE MISSION - 247-4B

DATE - September 4, 1974

TIME $\quad-10: 32 Z-13: 47 Z$

FLIGHT TRACK - Dakar $\rightarrow 18.16^{\circ} \mathrm{N}, 9.83^{\circ} \mathrm{W} \rightarrow$ Dakar

CSAS FLIGHT TRACK $-18.417,9.534 \rightarrow 17.658,11.1$

CSAS TIME - 12:10:00Z - 12:30:00Z; 0:20:00 Elapsed Time AIRBORNE MISSION SCIENTIST - Stephen K. COX

CSAS-248

GATE MISSION - 248-3

DATE - September 5, 1974

TIME $\quad-10: 39 Z-13: 17 Z$

FLIGHT TRACK - Dakar $\rightarrow 12.5^{\circ} \mathrm{N}, 16.6^{\circ} \mathrm{W} \rightarrow 13.0^{\circ} \mathrm{N}, 12.1^{\circ} \mathrm{W} \rightarrow 14.0^{\circ} \mathrm{N}:$ $13.4^{\circ} \mathrm{W} \rightarrow$ Dakar

CSAS FLIGHT TRACK $-12,582,16.617 \rightarrow 13.033,12.117 \rightarrow 13.938,13.418$ CSAS TIME - 11:04:20Z - 12:27:00Z; 1:22:40 Elapsed Time AERBORNE MISSION SCIENTIST - Bruce A. ATbrecht 
The albedo maxima and minima for the land portions of each flight are given after each table. The values obtained over water are given when applicable. The time and location values are those of the midpoint of each $20 \mathrm{~nm}$ flight track segment. 
CSAS-252

$$
\begin{aligned}
& \text { GATE MISSION - 252-2 } \\
& \text { DATE - September 9, } 1974 \\
& \text { TIME } \quad-14: 00 Z-16: 10 Z \\
& \text { FLIGHT TRACK - Dakar } \rightarrow 18.16^{\circ} \mathrm{N}, 9.83^{\circ} \mathrm{W} \rightarrow \text { Dakar } \\
& \text { CSAS FLIGHT TRACK }-18.426,9.514 \rightarrow 17.633,11.250 \\
& \text { CSAS TIME - 15:34:23Z - 15:00:18Z; 0:25:55 Elapsed Time } \\
& \text { AIRBORNE MISSION SCIENTIST - Bruce A. ATbrecht }
\end{aligned}
$$

\subsection{Aibedo Data Analys is}

In order to accurately present the measured surface albedo, each of the CSAS flight tracks was divided into segments of approximately 20 nautical miles $(\mathrm{nm})$ in length. The mean albedos measured along these $f^{\prime}$ ight track segments, the irradiance data, and the standard deviations are presented in Tables A7-A4 in the Appendix.

During the datta reduction procedure the data were systematically tested for credibility based upon the atmospheric conditions under which each mission was conducted. If an individual irradiance value failed any one of the specific credibility tests, it was omitted from the calculations of the means and standard deviations. The individual irradiance test criteria are given before each of the tables. This testing procedure was considered necessary in order to eliminate the bias in the albedo values due to a heterogeneous cloud cover and irregular surface illumination. It also omitted data obtained during periods of unusual aircraft attitudes (i.e. rapid ascent, descent, and banking) and any obvious instrument errors that may have occurred in flight. 


\subsection{ALBEDO INFERENCE TECHNIQUE}

The albedo inference technique makes use of the relationship between the bulk radiative properties of a one-layer atmospheric model bounded by a partially reflecting, homogeneous surface (Fig. 3). With a

$$
\begin{aligned}
& 12.5 \mathrm{~km} \mathrm{H}{ }_{1}^{+} \quad \mathrm{H}_{1}^{\uparrow} \\
& \text { Surface } \frac{{ }^{H}{ }_{S F C}}{11 / 111111 / 11111}
\end{aligned}
$$

Figure 3. A one-layer atmospheric model bounded by a partially reflecting, homogeneous surface.

knowledge of some of these properties over a certain geographical region, the remaining properties may be inferred. Specifically, the inference technique will provide a method for deducing surface albedo from satellite measurements of the earth-atmosphere reflectivity.

\subsection{Radiation Budget Equation}

The radiation budget equation that applies to this type of surfaceatmosphere model is derived from the conservation of incident energy $\left(H_{1} \downarrow\right)$ at the top of the model, which states that

$$
\mathrm{H}_{1}+=\mathrm{H}_{1} \downarrow \rho+\mathrm{H}_{1} \downarrow \mathrm{a}+\mathrm{H}_{1} \downarrow \tau
$$

where $\rho, a$, and $\tau$ are reflectivity, absorptivity, and transmissivity, respectiveiy. A similar derivation was reported by Cox (1975).

The reflected and absorbed energy may be partitioned such that they apply to either the surface-atmosphere system (SYS), the surface alone $(\mathrm{SFC})$, or the atmosphere alone (AT). Since all of the incident energy is either reflected or absorbed by the system, the transmissivity of the system is considered zero. However, the transmissivity through the atmosphere remains an important parameter in the budget. 
With these definitions,

$$
\begin{aligned}
& \rho_{S Y S}={ }^{\rho_{A T}}+\rho_{S F C} \\
& a_{S Y S}=a_{A T}+a_{S F C} .
\end{aligned}
$$

In terms of the irradiances in Fig. 3, these parameters are defined as follows. The subscript (1) refers to the top of the atmosphere.

$$
\begin{aligned}
& \rho_{S Y S}=\frac{H_{1} \uparrow}{H_{1} \downarrow} \\
& a_{A T}=\frac{H_{1} \downarrow-H_{1} \uparrow}{H_{1}+}-\frac{H_{S} S C-H_{S F C}}{H_{1}+} \\
& \tau_{\text {AT }}=\frac{H t_{S F C}}{H_{1}{ }^{\natural}} \\
& \alpha_{S F C}=\frac{H_{S F C}}{H_{S F C}}
\end{aligned}
$$

Using the relationships established by Eqs. 11 and 12, the conservation of energy identity of the system may be obtained by dividing Eq. 10 by $\mathrm{H}_{1}^{\text {iे, resulting in }}$

$$
1=p_{S Y S}+a_{A T}+a_{S F C} \cdot
$$

By defin'ng $a_{S F C}$ as the net energy at the surface with respect to the energy incident on the top of the model, $a_{S F C}$ may be written as

$$
a_{S F C}=\tau_{A T}\left(1-\alpha_{S F C}\right)
$$

where $\alpha_{S F C}$ is the surface albedo.

Substituting Eq. 18 into Eq. 17 yields the budget equation that is used in the aibedo inference technique,

$$
1=\rho_{S Y S}+a_{A T}+\tau_{A T}\left(1-a_{S F C}\right)
$$


The mean irradiance values used in Eqs. 13-16 were measured during CSAS-247 and are summarized in the following table.

\begin{tabular}{lccc} 
& MEAN & $\sigma$ & Percent of $\mathrm{H}_{1}{ }^{+}$ \\
\cline { 2 - 4 } $\mathrm{H}_{1}{ }^{+}$ & 1341 & - & - \\
$\mathrm{H}_{1} \uparrow$ & $390^{*}$ & - & 29 \\
$\mathrm{H}_{\text {SFC }}$ & 1056 & 47.2 & 79 \\
${ }_{\mathrm{H}}{ }_{\text {SFC }}$ & 448 & 23.4 & 33 \\
${ }_{\text {a }}$ & .42 & .026 & -
\end{tabular}

Table 3. Measured irradiances during CSAS-247, September 4, 1974, 1130 LST. A11 means and standard deviations ( $\sigma$ ) are in Wm-2. Hit is a 1200 LST calculation of the mean solar constant (1380 $\left.\mathrm{Wm}^{-2}\right)$ corrected for sun-earth distance variation.

\subsection{Remote Sensing by Satellite}

Since the characteristics of the earth's surface are being inferred by observing the radiative properties of the atmosphere above, the most powerful tool for an accurate, single-time look at a very large area is the Synchronous Meteorological Satelifte. The SMS-1 satellite with $2 \mathrm{~nm}$ resolution (Smith and Vonder Haar, 1976) provides a nearly instantaneous visible picture of the shortwave $(.55-.75 \mu \mathrm{m})$ radiation budget at the top of the atmosphere, if the picture brightness is interpreted as a measure of the earth-atmosphere reflectivity (osys).

The total shortwave reflectivity of the earth-atmosphere system is heavily weighted in the visible portion $(.4-.7 \mu \mathrm{m})$ of the solar spectrum

\footnotetext{
*Wile all irradiance values were collected over the same geographical location, $H 7 \uparrow$ was measured 20 minutes before the other values. Because $\mathrm{H}_{1} \uparrow$ was measured as a percentage of $\mathrm{H}_{1} \downarrow$, it is a good assumption that there will be little variation in this value during the 20 minute interva?.
} 
$(.2-4.0 \mu \mathrm{m})$ since nearly all of the absorption of the solar radiation occurs at wavelengths less than $.3 \mu \mathrm{m}$ and larger than $.76 \mu \mathrm{m}$. This is especiaily true in moist tropical regions where the absorption due to water vapor in the troposphere within the .7 to $3.0 \mu \mathrm{m}$ spectral interval would be abnormally strong. Because of this spectral selectivity, most of the irradiance arriving at the earth's surface and reflected out of the system is within the visible wavelengths. The visible range also contains 41 percent of the total solar energy incident on the earth (Robinson, 1966). It is for these reasons that the visible sensor (.55 $.75 \mu \mathrm{m})$ of the SMS-1 is considered a reasonable measure of the total shortwave reflectivity.

In order for the reflectivity at the top of the atmosphere to reveal anything about the underlying surface, something must be known about the nature of the atmosphere in between. Its radiative properties may vary significantly depending on moisture content, aerosols: sun angle, and cloudiness." If ye systematically deal with these variables, then the radiation budget at the top may indeed tell us something about the radiation budget at the bottom.

If we examine a form of Eq. 19, we see that

$$
\rho_{S Y S}=1-a_{A T}-\tau_{A T}\left(1-\alpha_{S F C}\right) \text {. }
$$

Since the atmospheric transmissivity $\left(\tau_{A T}\right)$ may be calculated from the same near-surface aircraft data set $\left(\tau_{A T}=H_{\psi_{S F C}} / H_{7} \downarrow\right)$, the average $\tau_{A T}$ may be determined aiong all of the CSAS flight track segments. (See Table 4.) Again, only irradiance data that pass the test criteria (Sec. 2.4) are used in the $\tau_{A T}$ calculations. This leaves only the estimates of the atmospheric absorptivity $\left(a_{A T}\right)$ in order to calculate the system reflectivity ( $\rho_{\text {SYS }}$ ) in Eq. 20. 


\subsection{Estimates of Atmospheric Absorptivity}

Atmospheric absorptivity was actually measured during only one of the CSAS missions. This occurred during the high and low-1evel portion of CSAS-247 as described in the Appendix. The atmospheric conditions on that day showed an extensive Saharan dust layer with a top at $5.5 \mathrm{~km}$ (Kondratyev, et a1., 1976) and a very low atmospheric water vapor content. The absorptivity as defined in Eq. 14 was .24 to .26 and is consistent with the findings of Kondratyev, et a1., 1976, in their analysis of the radiative properties of the aerosols in the Sahara region.

For the other CSAS missions an estimate of $a_{A T}$ was made based on the water vapor content measured during the filights and the observations of the nature of the aerosol layer made by a review of the flight films. Over the tropical rain forest during CSAS-248 and the southern leg of CSAS-243, a $a_{A T}$ was estimated to be .20 to .21 . These values agree well with the moist environment calculations of Vonder Haar and Hanson, 1969, who have stated that atmospheric absorptivity values may be 44-64 percent greater in the moist tropics than previously estimated. For conditions falling between the extremes of desert and tropical rain forest, in situations of moderate atmospheric moisture and increasing amounts of aerosols, $a_{A T}$ was estimated to be .22 to .23. These figures follow those of the annual global mean as presented by London and Sasamori, 1971. They refer to the strong influence of atmospheric dust on solar radiation absorption.

In summary,

$$
\begin{aligned}
& \text { CSAS-248, } 243 \text { (South) } \\
& \text { high moisture } \\
& \text { low aerosol } \\
& a_{A T}=.20 \text { to } .21 \\
& \text { CSAS-243 (North) } \\
& \text { moderate moisture } \\
& \text { increasing aerosols } \\
& a_{A T}=.22 \text { to } .23
\end{aligned}
$$


CSAS-247, 252

low moisture

high aerosol

$$
a_{A T}=.24 \text { to } .26
$$

\subsection{Brightness vs. PSYS Algorithm}

With values of $\tau_{A T}$ and $a_{A T}$, it becomes possible to rearrange $E q .20$ and solve for the $\alpha_{S F C}$ of a specific point, if the ${ }_{\text {SYS }}$ is known for that point. This rearrangement resuits in Eq. 21 .

$$
a_{S F C}=1-\frac{\left(1-\rho_{S Y S}-a_{A T}\right)}{\tau_{A T}}
$$

Since the satel7ite brightness count (B) may be interpreted as a measure of SSYS $_{\text {S }}$ it is possible to develop an algorithm that will produce the ${ }^{a}$ SFC for a given brightness.

The aigorithm is based upon the brightness values measured over the CSAS flight tracks where all of the bulk radiative properties of the surface and atmosphere are either measured or estimated. Once this algorithm has been established and tested, it may be applied to other areas within the CSAS region in which the atmospheric characteristics are similar to those used in the development of the algorithm.

It was determined that a $20 \times 20 \mathrm{rm}$ grid would be used in the algorithm cievelopment. With the averaging of both the $\alpha_{S F C}$ and $B$ on this grid scale, the influences of undetectable cloudiness and instrument noise are minimized. However, this grid scale $\left(1 / 3^{\circ} \times\right.$ $1 / 3^{\circ}$ ) is fine enough to resolve the surface reflectivity characteristics in detail.

Mean ${ }^{\text {SFC }}$ and standard deviations $(\sigma)$ for $20 \mathrm{~nm}$ segments of the CSAS flight tracks are presented in Tables A1-A4. The predominant surface classification (Sec. 3.5) of each of these segments is also 
given in these tables. The individual brightness values $(2 \mathrm{~nm}$ resolution) of the SMS-1 were averaged into $20 \times 20 \mathrm{~nm}$ mean values to be compatible in size with the $\alpha_{\text {SFC }}$ means.

Figure 4 is a scatter diagram of the mean brightness values (B) measured over the CSAS flight tracks at $1200 Z$ on September 4, 1974. The high concentration of points around $\alpha_{\text {SFC }}=.15$ to .25 and $\alpha_{\text {SFC }}=$ .43 results from the dominance of surfaces with these reflecting properties during September. The absence of statistics for surface class 5 (Sec. 3.6) is due to the lack of data over that particular surface type during that time of year. However, it may be seen that a strong correlation exists between $B$ and $\alpha_{\text {SFC }}$ regardiess of any gaps in the data.

By reducing the mean error to its most insignificant level (Panofsky and Brier, 1958), it was determined that a curve (solid line) defined by a second-order polynomial produced the best statistical fit between $B$ and $a_{S F C}$. The form of the polynomial and the values of the coefficients are given below.

$$
a_{S F C}=C_{0}+C_{1} B+C_{2} B^{2}
$$

where $c_{0}=-1.82454322 \times 10^{-2}$,

$$
\begin{aligned}
& c_{1}=6.722495 \times 10^{-4}, \text { and } \\
& c_{2}=1.70706 \times 10^{-5} .
\end{aligned}
$$

The range bars (Fig. 4) on this best fit curve represent the mean departure of the $\alpha_{S F C}$ values from this curve of $\alpha_{S F C}= \pm .02$. It should be kept in mind that the curve is only a depiction of the relationship existing at $1200 \mathrm{z}$ on September 4, 1974. Nothing more should be inferred from this figure until a complete understanding of the radiative properties of the atmosphere in between is attained. 


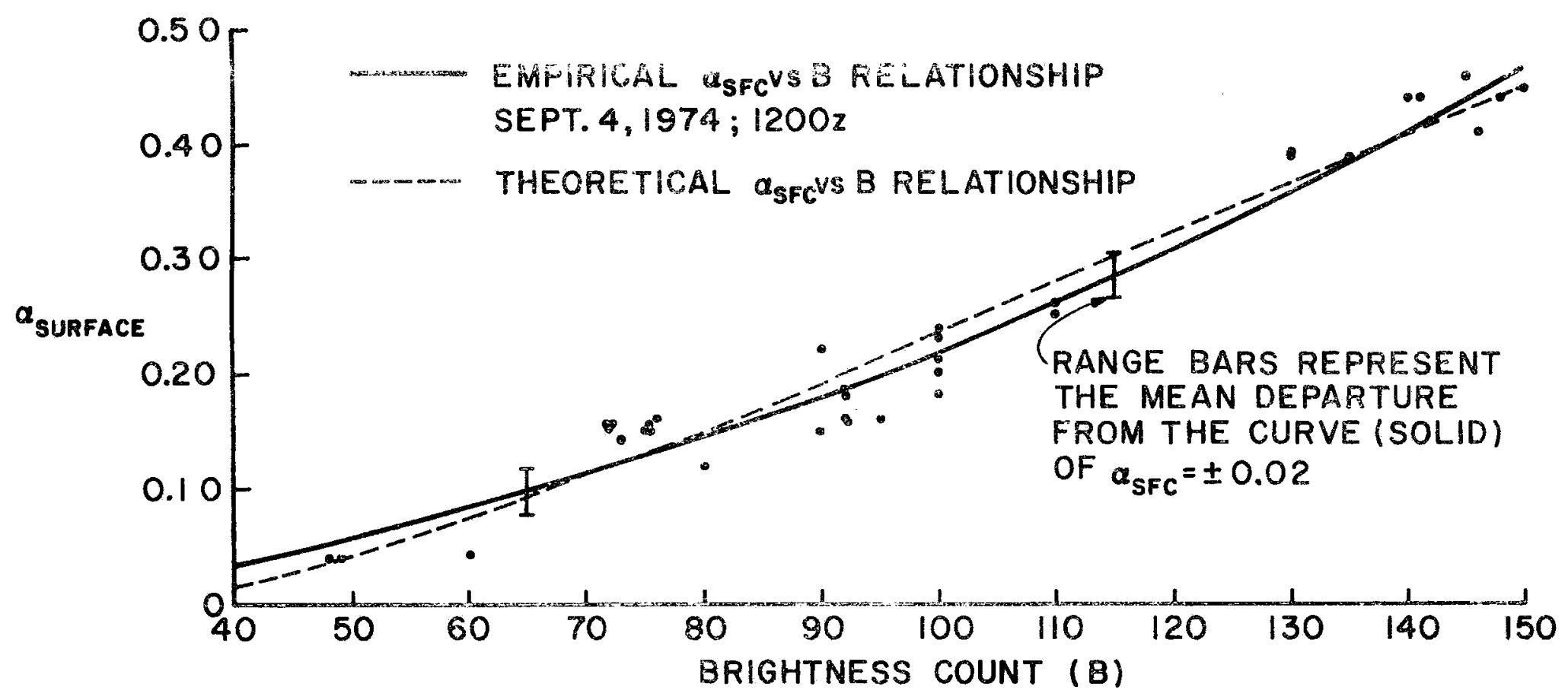

Figure 4. Scatter diagram of the empirical relationship between mean surface albedo $(\alpha S F C)$ and mean SMS -1 brightness count (B) over the CSAS region on September 4, 1974 at 12002. The solid line is the best fit using a second order polynomiat. The dashed line is a theoretical relationship resulting from a linear relationship between psys and $B$. 
From the ${ }^{\alpha}$ SFC curve of Figure 4 it is now possible to solve for the resulting PSYS values, at that particular time and place, by using the ${ }^{\tau} A T$ and $a_{A T}$ values in Eq. 20. The solid line of Figure 5 is the result of these calculations. The range bars on this curve are a manifestation of the range bars on the $\alpha_{S F C}$ curve.

The equation for the curve describing the relationship between ${ }^{\rho}$ SYS and $B$ in Figure 5 is as follows:

$$
f_{S Y S}=C_{0}+C_{1} B+C_{2} B^{2}
$$

where $C_{D}=8.02462535 \times 10^{-2}$,

$$
\begin{aligned}
& c_{1}=2.266234 \times 10^{-4}, \text { and } \\
& c_{2}=8.5864 \times 10^{-6} .
\end{aligned}
$$

The ${ }_{\text {SYS }}$ is expressed as both a fraction of the incident energy $\left(H_{7} \downarrow\right)$ and as reflected energy $\left(\mathrm{H}_{1} \uparrow\right)$. The zenith angle corrected solar constant $\left(H_{7} \downarrow\right)$ is $1366 \mathrm{Wm}^{-2}$ on September 4, 1974 at 12002.

This brightness vs. 's SYS relationship is only valid over the CSAS region at 12002 when it has been predetermined that similar $a_{A T}$ and ${ }^{\tau} A T$ conditions are present.

Tabie 4 summarizes the findings of the relationship between the bulk radiative properties of the surface and atmosphere over the CSAS region on September 4, 1974 at 1200Z. These properties are related through Eq. 20, and should not be used to prove energy conservation in a model other than one having a reflecting surface. 

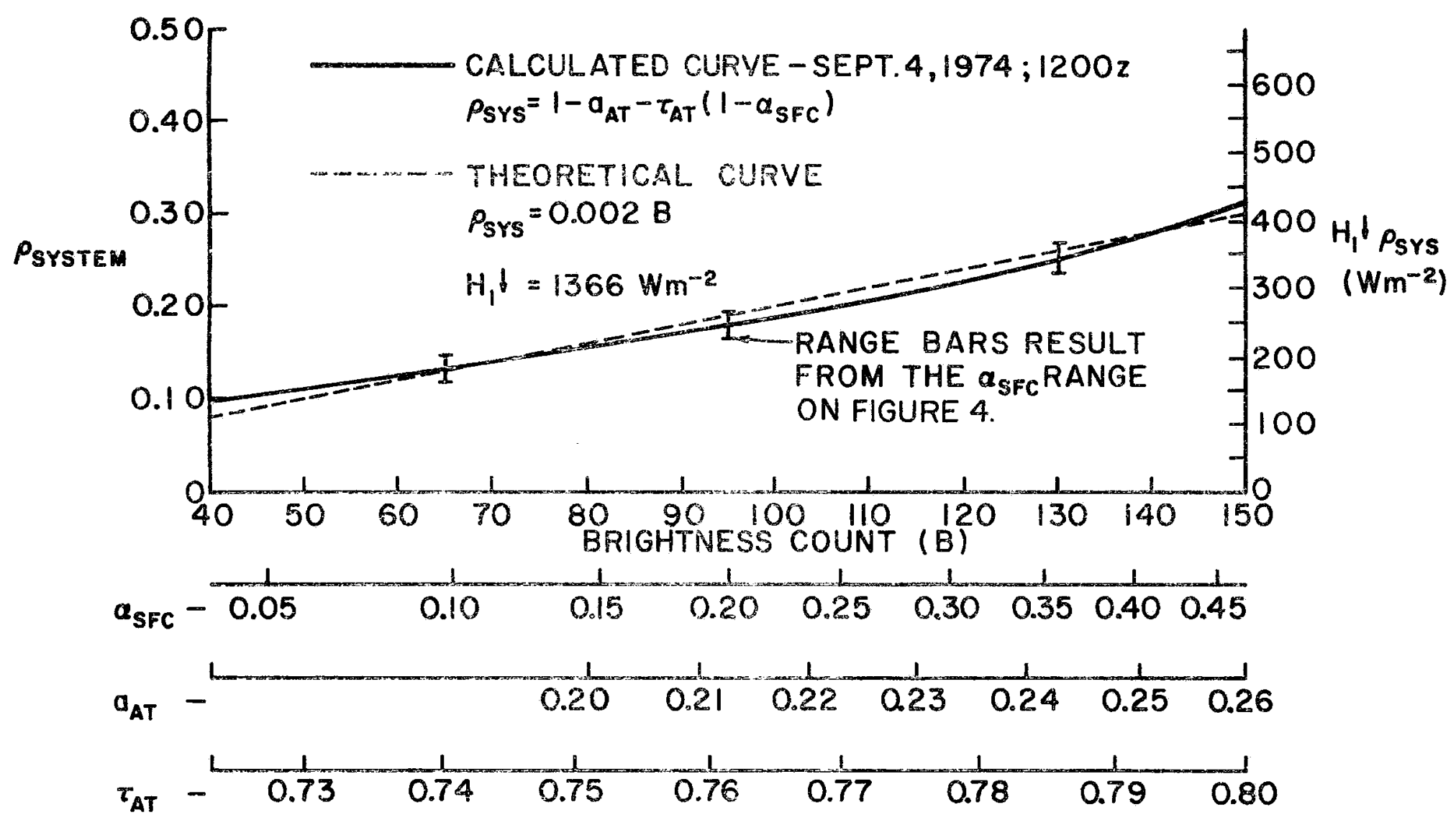

Figure 5. Relationship between roflectivity of the earthatmosphere system (osys) and mean SMS-1 brightness count (B) over the CSAS region on September 4, 1974 at 1200z. The solid line is calculated using the values of the three abscissas in Eq. 20. The dached line is a theoretical estimate of the PSYS - B relationship. 


\begin{tabular}{cccccc}
$B$ & $\overline{\alpha_{S F C}}$ & $\overline{a_{A T}}$ & $\overline{{ }^{\tau} A T}$ & $\overline{{ }^{\rho} S Y S}$ & $\overline{H_{T} \uparrow}\left(\mathrm{Wm}^{-2}\right)$ \\
\hline 40 & .04 & .20 & .73 & .10 & 137 \\
50 & .06 & .20 & .73 & .11 & 150 \\
60 & .08 & .20 & .74 & .12 & 164 \\
70 & .11 & .20 & .74 & .14 & 191 \\
80 & .14 & .20 & .75 & .16 & 219 \\
90 & .18 & .21 & .76 & .17 & 232 \\
100 & .22 & .22 & .76 & .19 & 260 \\
110 & .26 & .22 & .76 & .21 & 287 \\
120 & .37 & .23 & .78 & .23 & 314 \\
130 & .35 & .24 & .79 & .25 & 342 \\
140 & .41 & .25 & .79 & .28 & 382 \\
150 & .47 & .26 & .80 & .32 & 437
\end{tabular}

Tabie 4. Brightness count (B) and the bulk radiative properties of the surface and atmosphere (Eq. 20) for the CSAS region on September 4, 1974 at 12002. $\mathrm{H}_{1} \uparrow=\rho_{\text {SYS }} 1366 \mathrm{Wm}^{-2}$.

It might be suggested that the relationship between the visible brightness count and the $\rho_{S Y S}$ shown in Figure 5 should be linear (dashed line) rather than the curve that is found empirically. However, it is the yoltage output of the satellite sensor that responds linearly to reflected energy, while the brightness count is then related to this voltage output through a form of a square root function (Smith and Vonder Haar, 1976). Using some preiliminary estimates of the conversion from voltage output to reflected energy, the relationship between brightness count and PSY becomes similar to the curve that is found empirically. Any minor dissimilarities may be attributable to the fact that the empirical relationship was determined using a combination of empirica1. estimated, and measured values. Further investigations into the actual calibration of the SMS-1 voltage output will also help in defining this relationship. 
The dashed curve on Figure 4 is the result of using the estimated $a_{A T}$ and measured $\tau_{A T}$ values in Eq. 21 along with a hypothetical, linear relationship between $B$ and PSYS $_{S}$ of ${ }_{\text {SYS }}=.002 B$. These hypothetical curves are provided to show that even if the $B$ vs. PSYS relationship were linear, the resulting B vS. aSFC relationship would still be nonlinear. It may be seen that the hypothetical B vs. a SFC curve is within the mean error bars of the empirical curve.

In order to justify the inclusion of the irradiance scaie in Figure 5 , the assumption must be made that the reflecting surface is isotropic. Since a reflectivity measurement from a fixed point (synchronous satellite) at a fixed time is a bi-directional reflectance measurement, the calculation of the reflected irradiance may only be made using the assumptions that the incident irradiance is known (solir constant) and that the directional characteristics of the reflecting surface are also known. It will be seen that an assumption of isotropy is rather poor.

It is generally agreed upon by most investigators (Brennan and Bandeen, 1970; Kriebe?, 1974; Coulson and Reynolds, 1971) that many surfaces do display varying degrees of anisotropy, depending mainly on surface features, solar zenith angle, diffusivity of incident radiation, and wavelength. Generaliy, it is the flat, uniform surfaces such as sand, low grasses, and water that are more anisotropic than the heterogeneous surfaces of jungles, hills, or forests.

These differing reflectivity characteristics lead to the speculation that the brighter surfaces would actually appear darker than they should, if the incident light was being reflected away from the satellite in a disproportionate amount. The heavily vegetated 
surfaces, having less anisotropy, would not have the same dark bias. This anisotropy consideration would tend to emphasize the curved

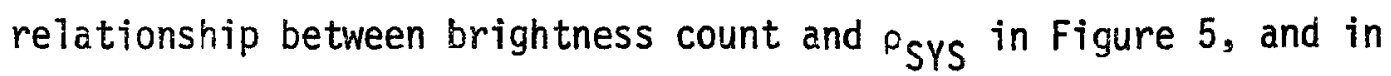
fact, would increase the similarity between the empirical curve and the curve resulting from the brightness count vs. voltage relationship. 


\subsection{Sensitivity of $\alpha_{S F C}$ to the Estimates of $a_{A T}$}

The only unmeasured variable used in the albedo inference technique is the atmospheric absorptivity, $a_{A T}$. This radiative property of the atmosphere was estimated using the results of past investigators for atmospheric conditions similar to those encountered during the CSAS. Throughout the explanation of the development of the technique it was stressed that strict adherence to similar $a_{A T}$ and $\tau_{A T}$ conditions must be maintained in order for the $B \rightarrow \rho_{S Y S} \rightarrow \alpha_{S F C}$ algorithm to be valid. However, $a_{A T}$ is probably the most difficult to measure of the radiative properties. Therefore, it is impontant to investigate the effect of an over or under estimate of $a_{A T}$ on the inferred albedo values.

Over the CSAS region three variables were measured; $\alpha$ SFC, $\tau$ AT, and $B$. $a_{A T}$ had to be estimated to solve Eq. 20 for ${ }^{P_{S Y S}}$. ${ }^{\alpha} S F C$, ${ }_{A T}$, and $B$ were, therefore, considered constant for that particular place and time. Using that assumption, Eq. 21 may be differentiated with respect to $a_{A T}$ with the result that

$$
\frac{d \alpha_{S F C}}{d a_{A T}}=\frac{1}{{ }^{\tau} A T}
$$

The implication of this differentiation is that for turbid atmospheres in which the transmissivity is reduced, the calculation of $\alpha_{S F C}$ by this technique is more dependent on an accurate estimate of $a_{A T}$ than in atmospheric conditions that are less turbid. Table 5 illustrates this point. 


\begin{tabular}{cccc}
$\begin{array}{l}\text { Percentage } \\
\text { Error in } \mathrm{a}_{\text {AT }}\end{array}$ & \multicolumn{3}{c}{${ }^{\tau_{A T}}$} \\
Estimate (I) & .70 & $\begin{array}{c}\text { (Percent) } \\
75\end{array}$ & 80 \\
\hline 5 & 7 & 7 & 6 \\
10 & 14 & 13 & 13 \\
15 & 21 & 20 & 19
\end{tabular}

Table 5. Percentage error in aSFC calculations due to an over or under estimate of aAT for three different transmissivity possibilities.

\subsection{Surface Classification System}

Since careful observations of the nature of the surface were made during the CSAS by both the airborre mission scientist and the aircraft's movie camera, it is possibie to infer more than a value of the surface albedo for a particular region. The surface albedo is a function of the soil, vegetation, and moisture characteristics of the surface, so it is reasonable that an inference of the albedo would aiso be an inference of the more descriptive properties of the surface. With this in mind, the flight films and observer's logs were reviewed with the intention of classifying the various surfaces according to the observabie features of soil type and color, vegetation type, color, and density, and general surface moisture conditions. Each frame of the four films was studied and then placed into one of eight (0-7) distinct surface classes. Independent of a knowledge of the surface classification, each frame was aiso assigned its albedo which had been measured by the aircraft irradiance measurement system. On the completion of both the surface type classification and the measured albedo classification, the two were combined to provide the mean albedo and albedo range that applied to each surface class. 
Table 6 summarizes the results of this stratification.

\begin{tabular}{|c|c|c|c|c|c|}
\hline CLASS & DESCRIPTION & $\begin{array}{l}\alpha_{S F C} \\
\text { MEAN }\end{array}$ & $\sigma$ & $\begin{array}{l}\alpha_{\text {SFC }} \\
\text { RANGE }\end{array}$ & $\begin{array}{l}\text { RANGE } \\
\text { EFFICIENCY }\end{array}$ \\
\hline 0 & $\begin{array}{l}\text { SWAMPLAND, OCEANS - coastal } \\
\text { Swamps, rivers smooth oceans; } \\
>50 \% \text { water with low solar } \\
\text { zenith angle }\end{array}$ & .09 & .015 & $\leq .10$ & 95 \\
\hline 1 & $\begin{array}{l}\text { DENSE FOREST - uniform dark } \\
\text { vegetation; } 10 \% \text { light vegeta- } \\
\text { tion or soils }\end{array}$ & .15 & .017 & $.10-.16$ & 91 \\
\hline 2 & $\begin{array}{l}\text { MODERATE FOREST - mostly dark } \\
\text { vegetation some light grasses } \\
\text { or soils; 30\% light vegetation } \\
\text { or soils }\end{array}$ & .17 & .021 & $.16-.27$ & 73 \\
\hline 3 & $\begin{array}{l}\text { MIXED VEGETATION - evenly mixed } \\
\text { surface; } 50 \% \text { dark vegetation; } \\
50 \% \text { ight vegetation or soils }\end{array}$ & .22 & .032 & $.27-.26$ & 73 \\
\hline 4 & $\begin{array}{l}\text { SAVAN:A - mostiy low, light } \\
\text { grass s, cultivated fields, } \\
\text { some ark scrub; 70\% light } \\
\text { dry grasses; } 30 \% \text { dark scrub } \\
\text { or rock }\end{array}$ & .28 & .025 & $.26-.37$ & 70 \\
\hline 5 & $\begin{array}{l}\text { MIXED DESERT - dry, light } \\
\text { surface, colored soils and rock } \\
\text { outcroppings; } 50 \% \text { light soils } \\
50 \% \text { s rub, light grasses }\end{array}$ & .33 & - & $.31-.36$ & - \\
\hline 6 & $\begin{array}{l}\text { MODERITE DESERT - sparse } \\
\text { vegetation, mostiy light sands, } \\
\text { scrub: 30\% low scrub, light } \\
\text { grassas, rock }\end{array}$ & .39 & .016 & $.36-.42$ & 98 \\
\hline 7 & $\begin{array}{l}\text { DESER: - uniform sand surface } \\
\text { little variation in surface } \\
\text { over large areas; 10\% low } \\
\text { scrut or colored rock }\end{array}$ & .43 & .021 & $\geq .42$. & 85 \\
\hline
\end{tabular}

Table 6. Surface Classification System. 
The standard deviation $(\sigma)$ of each class is the value for the albedo of each class. The Range Efficiency is the percentage of the number of film frames of a given class actually falling within the specitied albedo range. This percentage may be considered a measure of several things. First, it may be thought of as a measure of how well each class is defined. Obviously, it is easier to distinguish the extreme ciasses than it is to distinguish the middle classes. Second, it is a measure of the variable nature of the surface albedo in the middie classes (2-5). Finaliy, it may be considered a measure of the overlap between the surface classes. Since each frame was subjectiveiy analyzed, there are always some frames that could belong to the next higher or lower class. The Range Efficiency indirectly shows how often a frame may have belonged in a neighboring class. Class 5 has no statistics because there were not enough samples of this type of surface during the month of September. During a drier season (Nov. Apr.) this class would have been sampled more often.

Figure 6 shows the Surface Classification System superimposed on the B vS. "WFC curve of Figure 4. The length of each class box represents the class $\alpha_{\text {SFC }}$ range, and the width represents \pm one standard deviation $(\sigma)$ from the class mean.

It may be seen from Figure 6 that when the albedo inference technique is applied and an aSFC is derived from a brightness value (B) : that more than just a number is inferred. When the $\alpha_{S F C}$ is combined with the Surface Classification System, a more complete interporetion of the $\alpha_{S F C}$ value is obtained. 


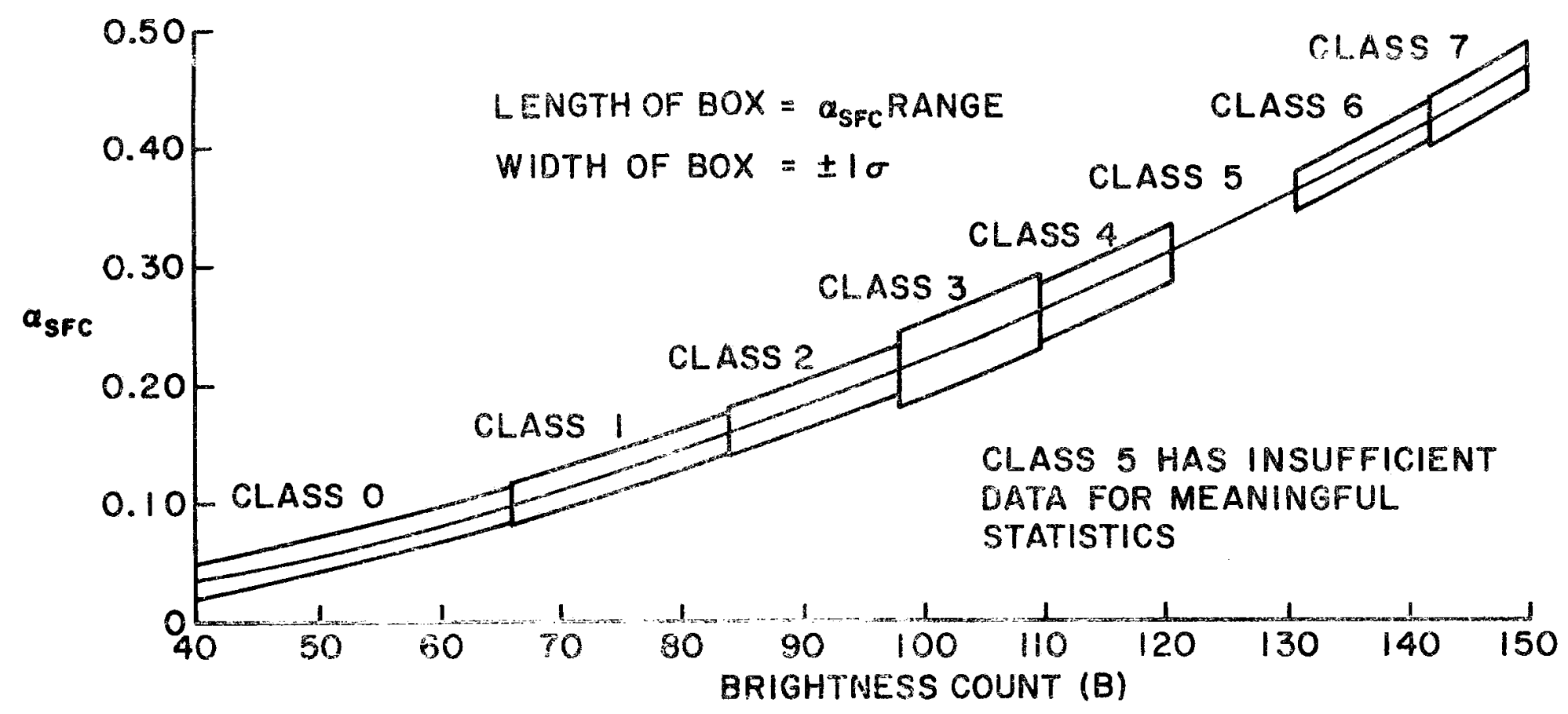

Figure 6. Surface Classification system superimposed on the PSYS vs. aSFC curve of Figure 4 . The phistical destiption of each c7ass is given in Sec. 3.E. 
3.7 Sumary of the Albeco Inference Technique

Figure? is used to summarize the steps involved in the development and application of the 3 bedo inference technique. A brief description of each step foliows the figure. This flow diagram summarizes the continuty and logic of the cechmoue.

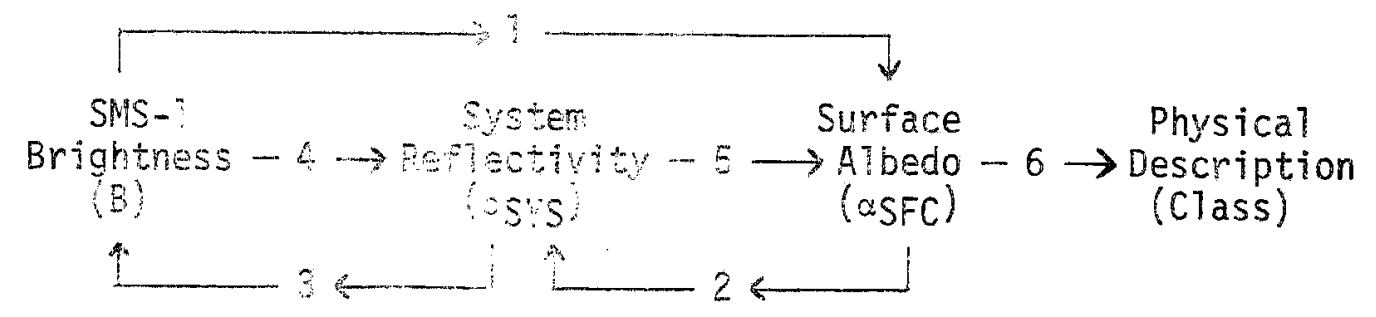

Figure 7 . Fow sogan of the albedo inference technique.

\section{DEVELJPMENT STEPS}

STEP 7 An empirice: petetions ip between the mean SMS-1 brightness data (b) and them CSAS surtace albedo $\left(a_{S F C}\right)$ is estab3roned. Obsamations of the physical characteristics of the surface are mage at chis sime. See Figure 4 and Eq. 22.

STEP 2 heasured atncsoneric transmissivity values $\left(\tau_{A T}\right)$ and estimated absorptinty values a are combined with the a SFC to produce the sumface - atmosphere reflectivity values ( $\left.\rho_{S Y S}\right)$. See Figure 5 and Eg. 20 .

STEP 3 Reiationshit is established between B and PSYs through steps 1 and 2. Ses Finge:

APPLILATION STEPS

STEP 4 An algorithm for the owartitative relationship between $B$ and Pgus estaphisher. See Eq. 23.

STEl 5 asfo is infermed fom os:s, provided that similar ${ }_{A T}$ and a condtituns ane used. Ses Eq. 21. 
STEP 6 The surface class (0-7) gives a physical description of the surface from the inferred $\alpha_{\mathrm{SFC}}$. See Table 6 and Figure 6 . 


\subsection{APPLICATION OF INFERENCE TECHNIQUE}

The albedo inference technique was appilied following a prescribed sequence of steps so that the comparison between inferred albedo values from different dates could be made with confidence. The $1200 Z$ SMS-1 brightnesS data for the CSAS region were averaged into $1 / 3^{\circ} \times 1 / 3^{\circ}$ mean values. The resulting matrix of mean values was gridded for navigational purposes, and any obvious geographical features (coastlines, river basins, istands, etc.) were outined for surface reference purposes. The actuel visible satelltte photograph that corresponds to the brightness data was carefully studied to determine the areas of detectable cloudiness. These areas were omitted from the brightness matrix since the infexence techique may not be used in regions of cloudiness. The inference technoue was applied to the remaining brightness values in the clear regions, and an analys is in terms of surface albedo was done on the brightness matrix. The isopleths chosen for this study were those defined by the divisions of the Surface Classification System, however, the brightness matrices may be analyzed using any isopleth definition destred. The isopleths chosen for this study were based on the surface classes so that the physical characteristics of the surface could be readily inferred. This isopleth spacing also heped to emphasize the areas of strong and weak albedo gradient. One may, of course, infer an albedo range for any individual brightness value by simply using figure 6 .

\subsection{Limitations of the Technique}

It is important at this time to review the limitations of the inference techntque. First, since the satellite brightness is directly a function of sur angle, the technique must be based on and applied to 
a specified satellite picture time. 12002 was used in the development of the technique because it provided the greatest brightness values; showed the greatest brightness contrast between surface features; minimized the effects of surface and cloud shadows; and corresponded to the CSAS-247 mission during which there was a minimum amount of cloudiness for good upper and lower level irradiance measurements. The variation in brightness due to solar declination variation is negligible in the tropical regions, however, this variation would become significant at higher latitudes during the course of a complete solar cycle.

It is a reasonable speculation that the brightness values observed at times other than local solar noon could be multiplied by the secant of the solar zenith angle, thereby making them useful as local noon values in the albedo inference technigue. Unfortunately, the correction of the brighoness count is not this straightforward. Remembering thet the brightness count is a nonlinear function of the voltage output of the radiancs sensor, it would be more reasonable to appiy the georetry correction to the voltage output (which is linear with respect to radiant energy) and then evaluate the brightness count generated from a corrected volt tage.

An ana" "sis of the $1 / 3^{\circ} \times 1 / 3^{\circ}$ mean brightness values over a $5^{\circ} \times 5^{\circ}$ area of the SSAS region for various hours during july 2, 1974 shcwed that the decrease in brightness from local solar noon did not respond according to the cosine function of the respective voltage output, but rather decreased more slowly. The following table shows the observed versus the expected decrease in the brightness count. The changes observer showed a high degree of symmetry about local noon. 


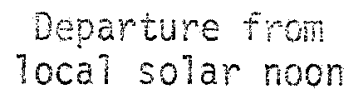

hours
Percentage Decrease in mean brightness count

Expected Observed

\begin{tabular}{lll}
\hline & 2 & 1 \\
2 & 6 & 5 \\
3 & 14 & 8 \\
3.5 & 19 & 16 \\
5 & 41 & 25 \\
\hline
\end{tabular}

Table 7 . A comparison of the expected versus the observed decrease in brightness count over the CSAS $\left(17.5^{\circ} \mathrm{N}\right)$ on sily 2, 974 . The expected decrease is based on the assumption that the voltage output for the respective brigituess values is a function of the costhe of the solar zenth angle.

The departure of the observec decrease from that expected is due in part to the preserce of an atmosphere in which the transmissivity and absorptivity chamacteristics vary with sun angle. This causes the reflectivity to vary with sun angle as well, but not as a simple cosine function. The observed ralues are also caused by the diffusivity and scattering properties of the atmosphere, which would allow for a greater amount of reflected radjance in the direction of the sensor than would be found in the hypothetical situation of no atmosphere. This is why there is stili some reflected energy even though the sun may be below the horizon. Fine? increase in the albedo of sertein surface types at large zenith angles.

A further analysis of these differences between the expected and observed brightness values may help to reveal and explain some adotitional interesting cheracteristics of both the atmosphere and surface. 
Second $y$, the technique was developed using the measured $\tau_{A T}$ and estimated $a_{A T}$ in order to solve for the ${ }_{\text {SYS }}$ at a particular place and time. In the application of the technique to other regions, it should initialiy be determined that similar radiative properties may be expected in the application region. Significant variation from these conditions (Table 4) could lead to a different B-psys relationship.

Thirdly, as a statement of the reliability of this technique, the Range Efficiency in Table 5 may be used as a measure of the technique accuracy. Thus, for the high and low classes $(0,1,6,7)$ the accuracy is greater than 85 percent. For the middie classes $(2,3,4,5)$ that are not as well defined geographically or radiatively, the accuracy decreases to near 70 percent.

Finally. it is stressed that all cloudiness must be eliminated from the application region before the technique is applited. Cloudine:s is not accouted for in Eq. 21. The albedos inferred in areas where high-level, undetectable cloudiness is suspected should be analyzed with caution.

\subsection{Albedo tap of the CSAS Region}

The inisial application of the technique was to determine the surface albedo of the local CSAS region using the 12007 brightness catr: or September 4, 1974. This region includes the CSAS flight tracks, which supplied the surface albedo values used in the technique development. Map 1 shows the result of the application. The presence of some thin cirrus is the probable cause of the surface class variations along the southern leg of CSAS-243. This emphasizes the need for a careful elimination of ail cloudiness using the visible photograph prior to the 
analysis stage. Figure 10 quantifies the strong albedo gradient that is evident in this region. Inferred aibedo values range from .45 to .10 using the technique.

\subsection{Examination of the Seasonal Variation of Surface Albedo}

One of the goals that was set for this study was to use the inference technique to examine the seasonal variation of the surface albedo over northwestern Africa. The technique has now been developed and tested in a region of known albedo, and it is now possible to use the technique to study this variation.

The seasonal migration of the intertropical convergence zone (ITCZ) is directly responstble for the large fluctuations in the availability of moisture for precipitation. This is dramatically pointed out in the results of an 11 year study of the specific humidity over northwestern Africa (Aspliden and Adefola7u, 1976). Figure 8 shows the annual trend of surface specific humidity at four stations in the $13^{\circ} \mathrm{N}$ to $14^{\circ} \mathrm{N}$ latituce beit. A strong seasonal variation in the low-level atmospheric water content is seen as the ITCZ traverses this latitude zone, reaching a maximum in September. In contrast, Figure 9 shows Tittle seasonal variation at the four southern stations located at about $5^{\circ} \mathrm{N}$. This latitude is nearly constantiy under the influence of low-level moisture convergence. As a consequence of this fluctuation in the atmospheric moisture availability, the northern region experiences distinct wet and dry seasons. The monsoonai nature of the annual rainfall also produces a significant seasonality in the vegetation characteristics of the surface. During the dry season (Nov.-Apr.) the surface is dominated by a sparse scrub type of vegetation and dry, loose soils. With the onset of the wet season (May-oct.) the surface features take on a much more 


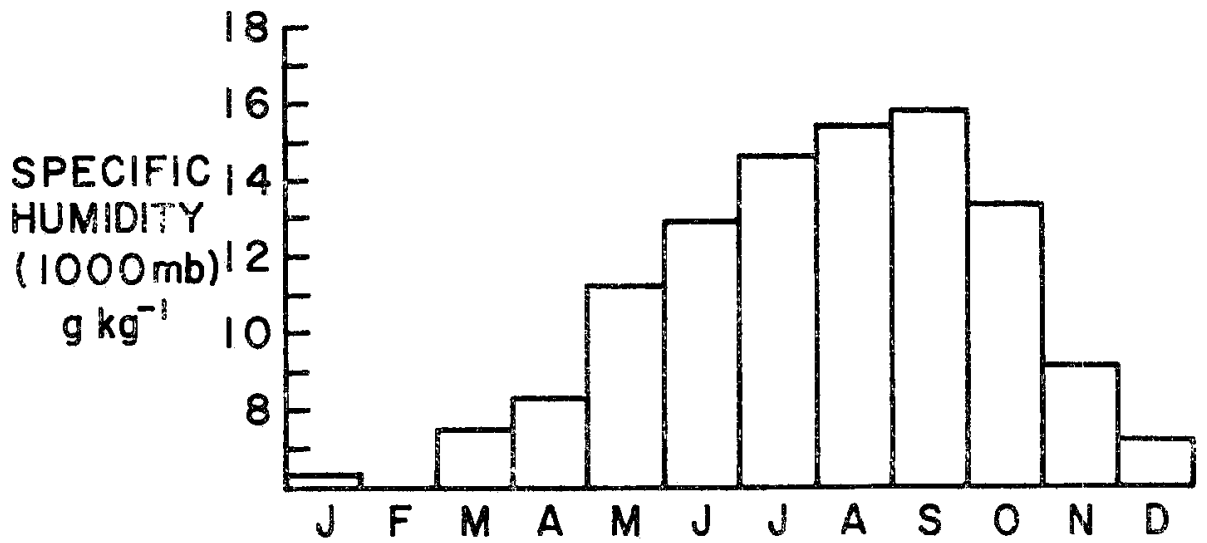

Figure 8. Mean $1000 \mathrm{mb}$ specific humidity during an 11 year period for West Africa, $73^{\circ} \mathrm{N}$. (Aspliden and Adefolalu, 1976.)

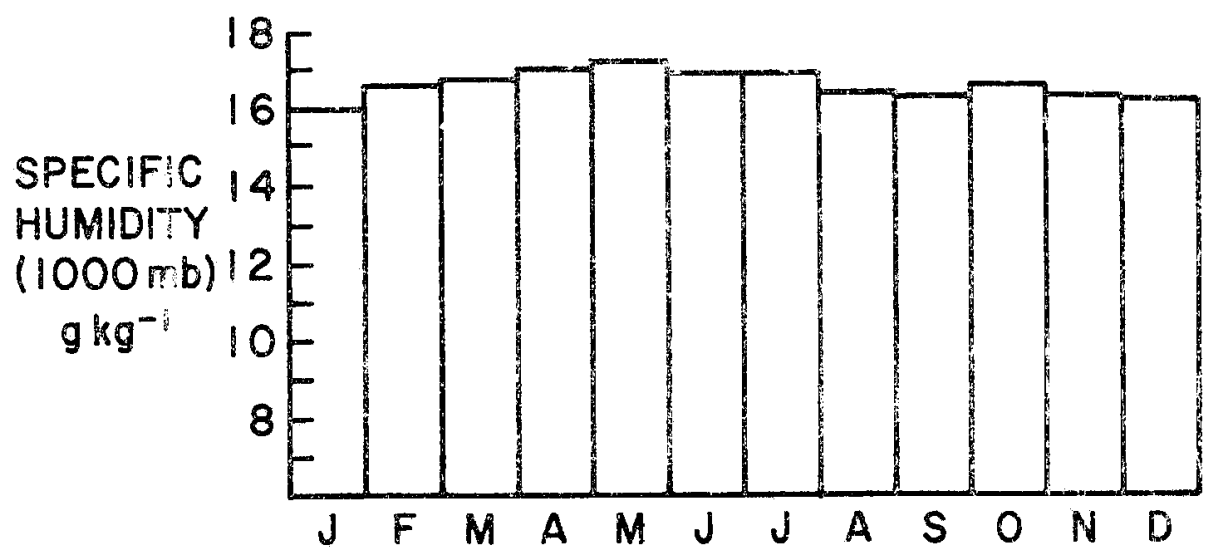

Figure 9. Mean $1000 \mathrm{mb}$ specific humidity during an 11 year period for West Africa, $5^{\gamma} \mathrm{N}$. (Aspliden and Adefolalu, 1976.) 


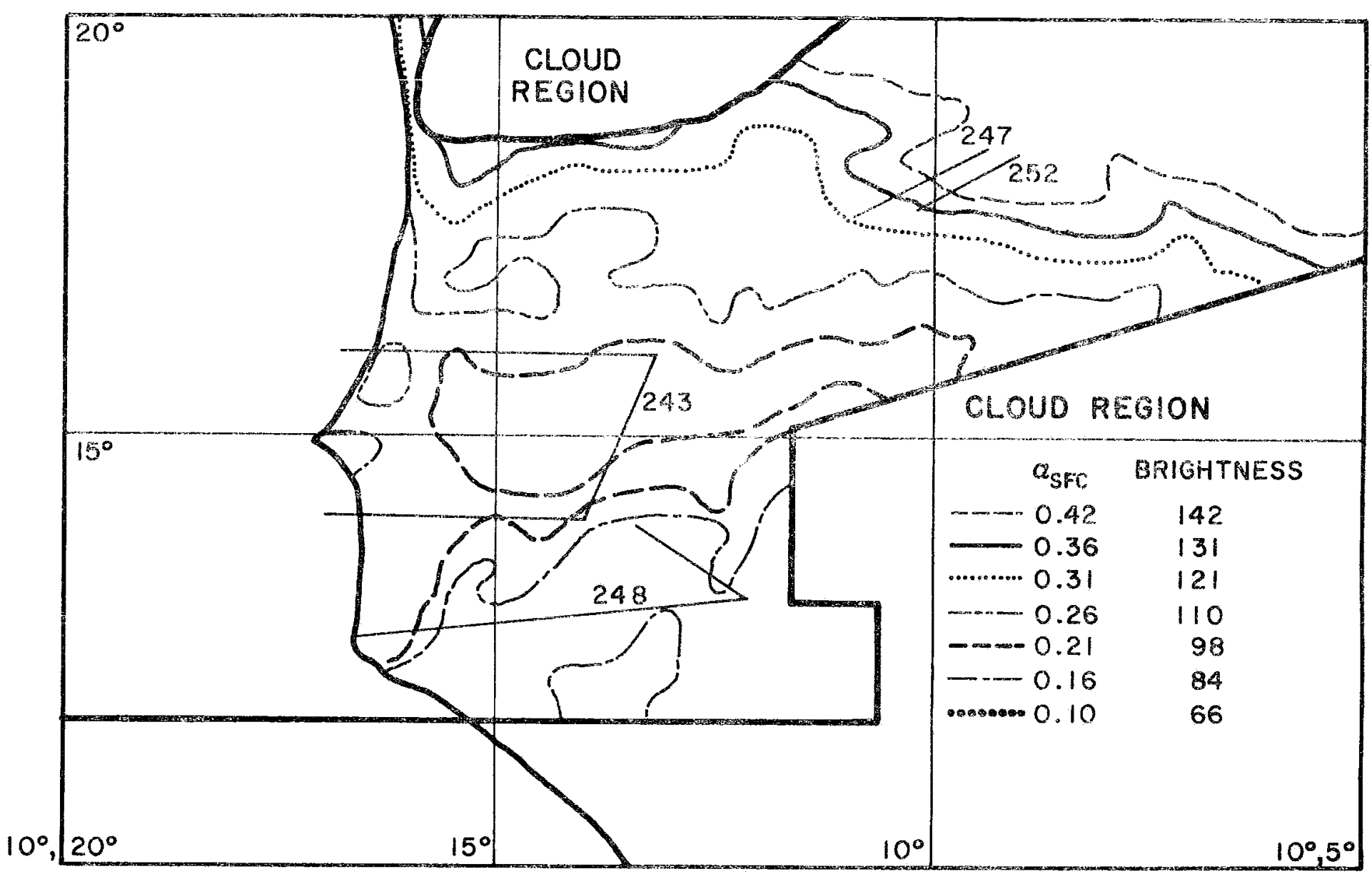

Figure 10. Surface albedo analys is of the CSAS region at 12002 on September 4, 1974 showing flight tracks designated by Julian day number. The contours correspond to the Surface Classification System. 
lush appearance as the vegetation fills out with leaves, and darker colored grasses develop. The soils become more compact and turn a somewhat darker color with the increase in water content. These are the changes in the surface features that are so evident when comparing the satellite photographs of this region during differerit seasons.

To study this variation, three relatively cloud-free days were selected; July 2, 1974 at the start of the GATE field operations, August 10, 1974, and September 20, 1974 at the end of the GATE. Although this 80 day interval is concentrated over the wet season, according to the 11 year study, the differences between early JuTy and late September are sufficient to show the value of the albedo inference techinique and the significance of the chariges in the surface albedo.

Figures 11,13 , and 15 are the surface 21 bedo analyses for July 2, 1974; August 10, 1974; and September 20, 1974, respectively. They ware generated from the 1200Z SMS-1 brightness data on their respective davs, and employed the albedo inference technique as specified in this stucy. In accordance with the limitations discussed in Sec. 4.1 , the assumptions of similar "AT and $\tau_{A T}$ were considered vaild for these days. The corresponding satelitte photographs accompany each figure.

\subsection{Discussion of the Resuits}

The most apparent difference that is manifested by the surface analysis is the change in the surface albedo gradient from July to September. Near the end of the dry season, the albedo gradient is comparatively weak since the surface in the southern region is dry and the vegetation is sparse and dormant. With the onset of the wet season the southern region becomes more densely covered with actively growing vegetation, and the surface becomes more absorptive to the sunlight. 

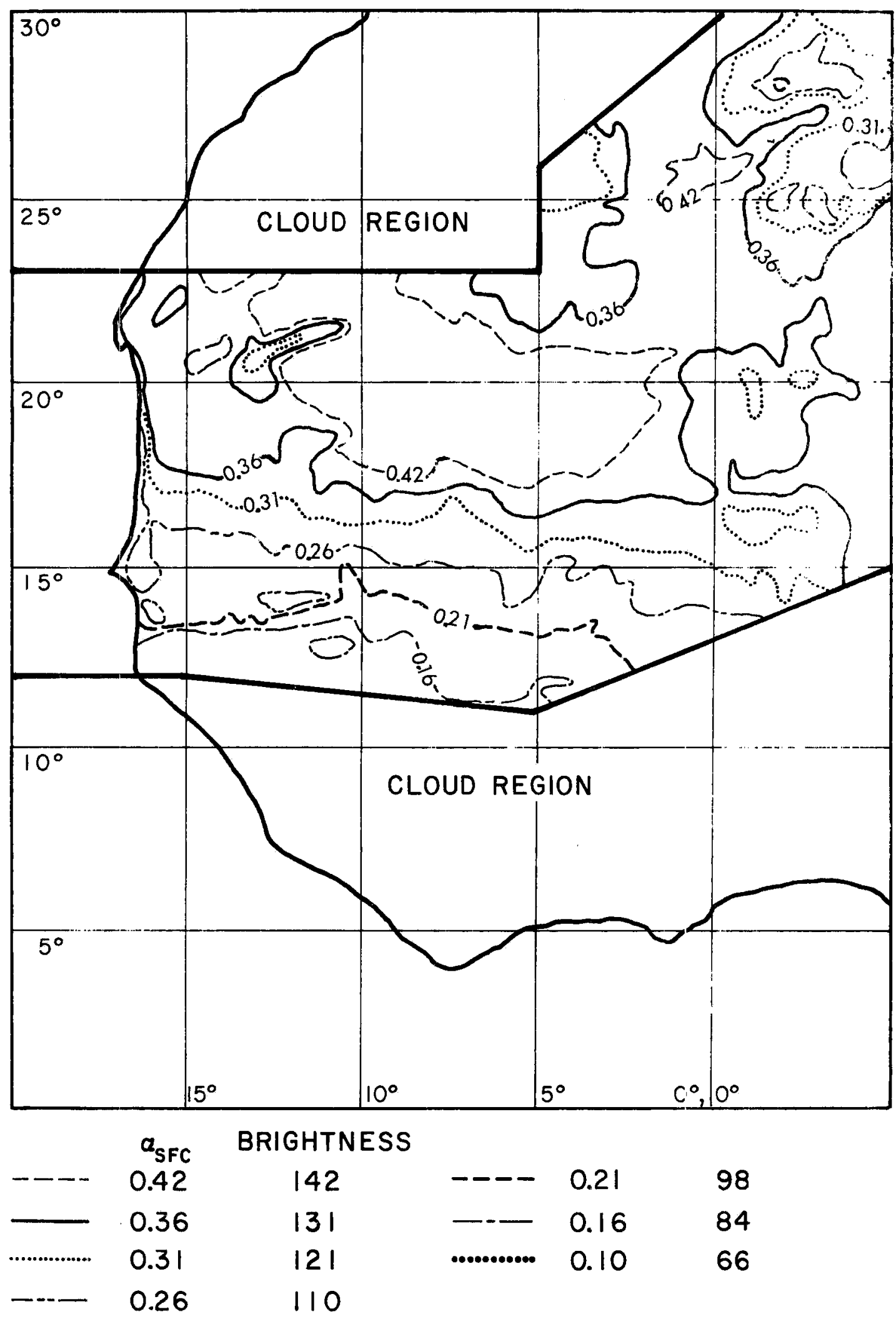

Figure 11. Surface albedo analysis for 12002 on Iuly 2, 1974. 


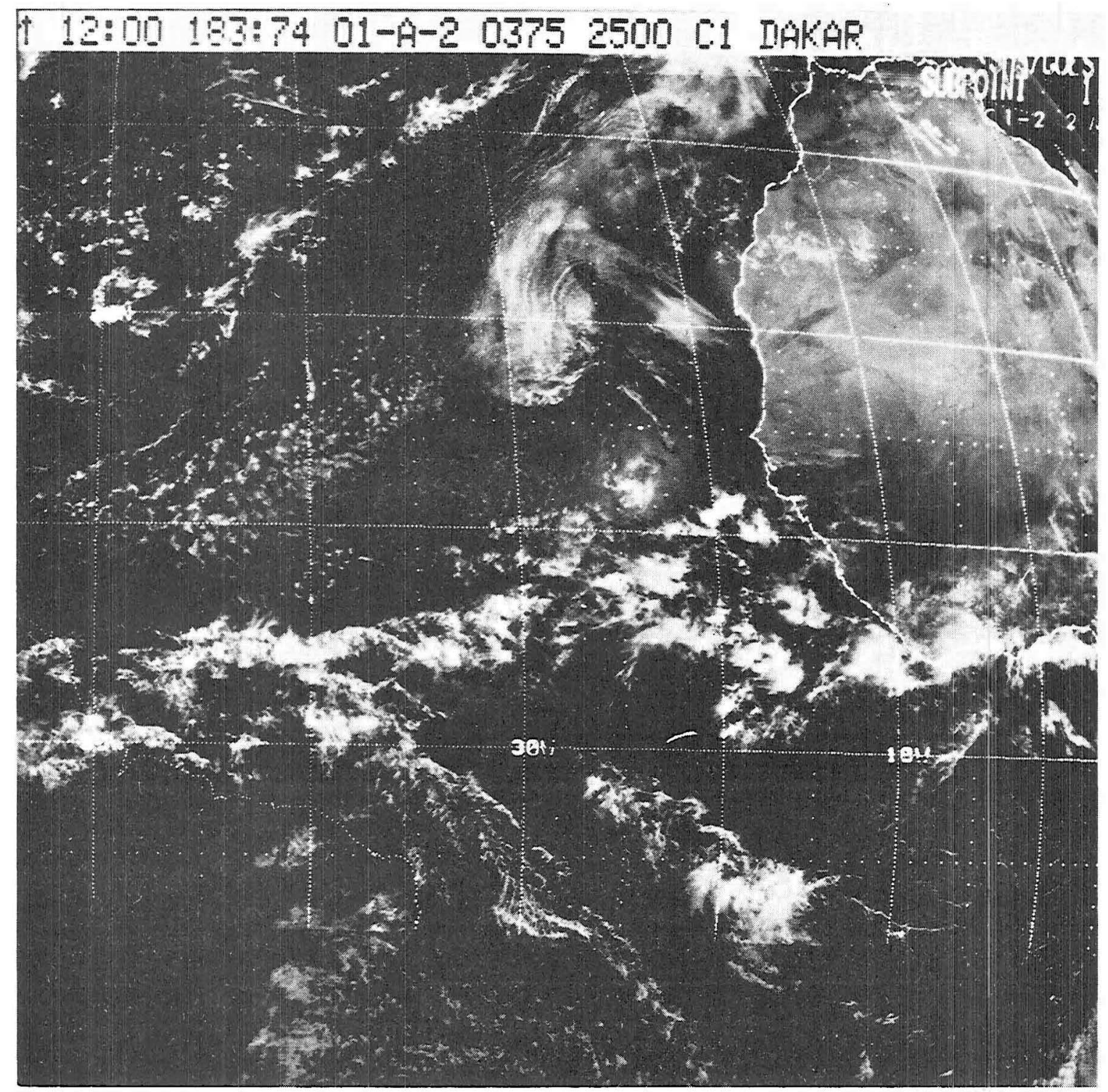

Figure 12. Visible photograph from SMS-1 satellite at $1200 Z$ on July 2, 1974. 


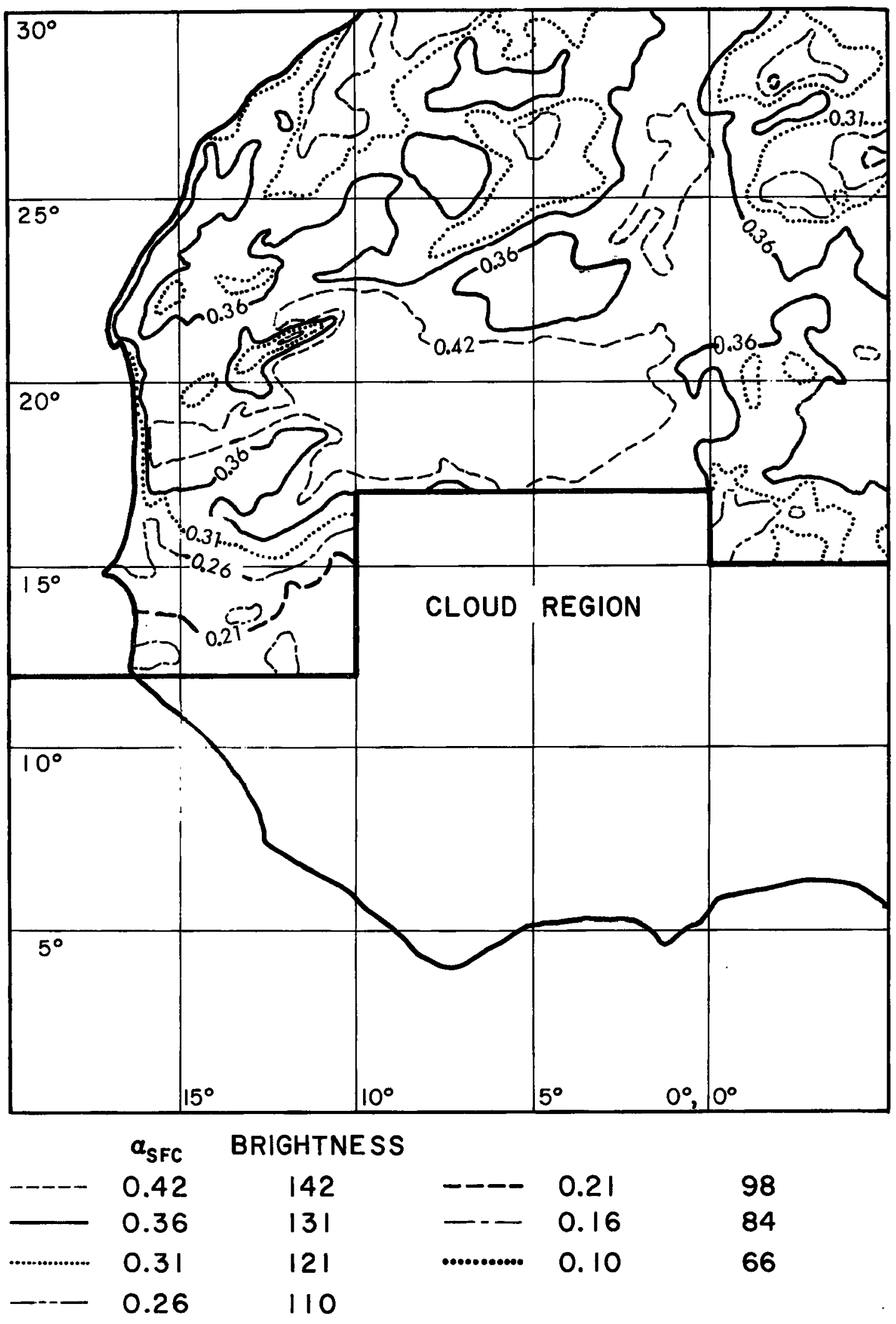

Figure 13. Surface albedo analys is for 12002 on August 10, 1974. 


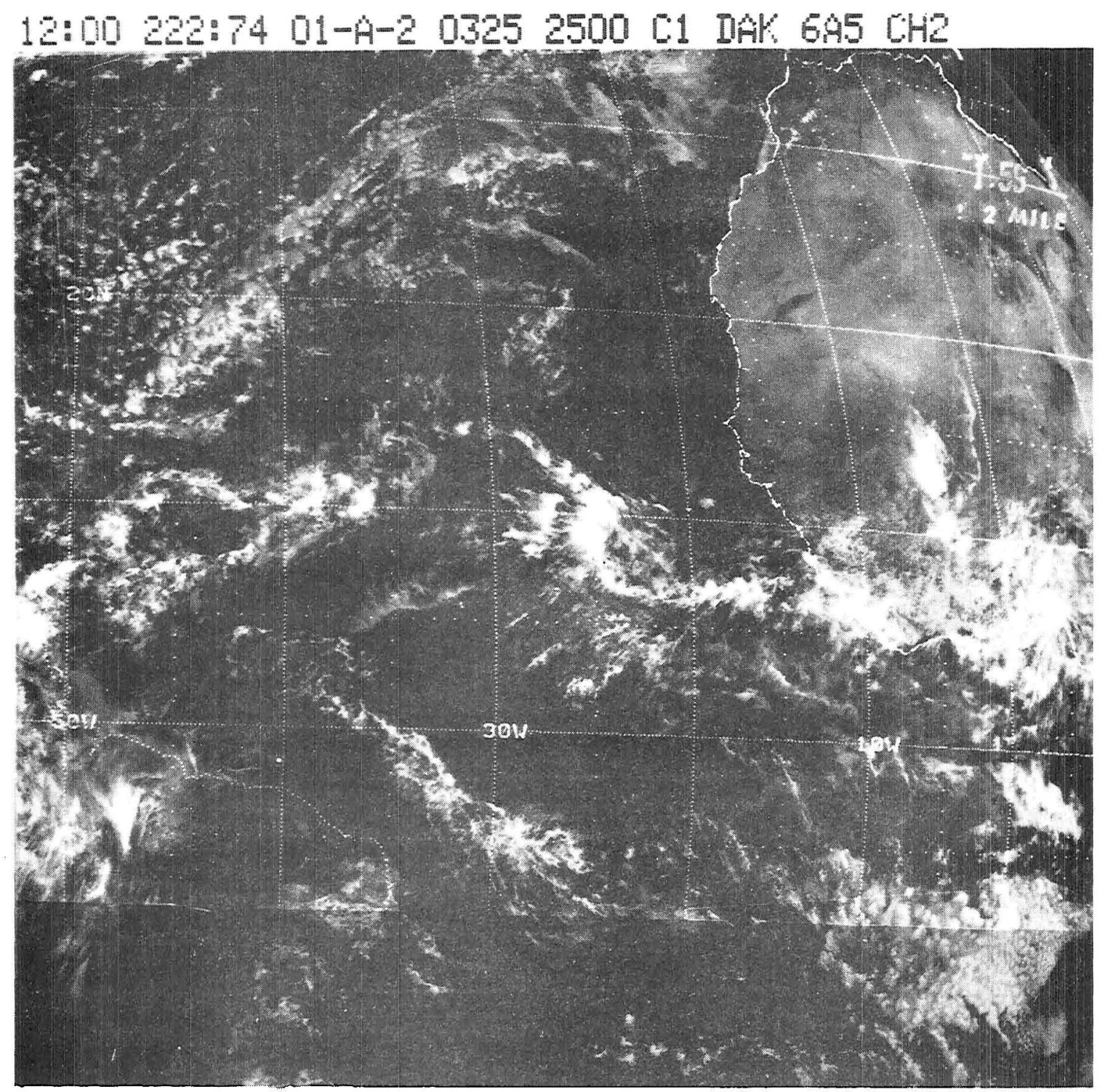

Figure 14. Visible photograph from SMS-1 satellite at $1200 \mathrm{z}$ on August 10, 1974. 


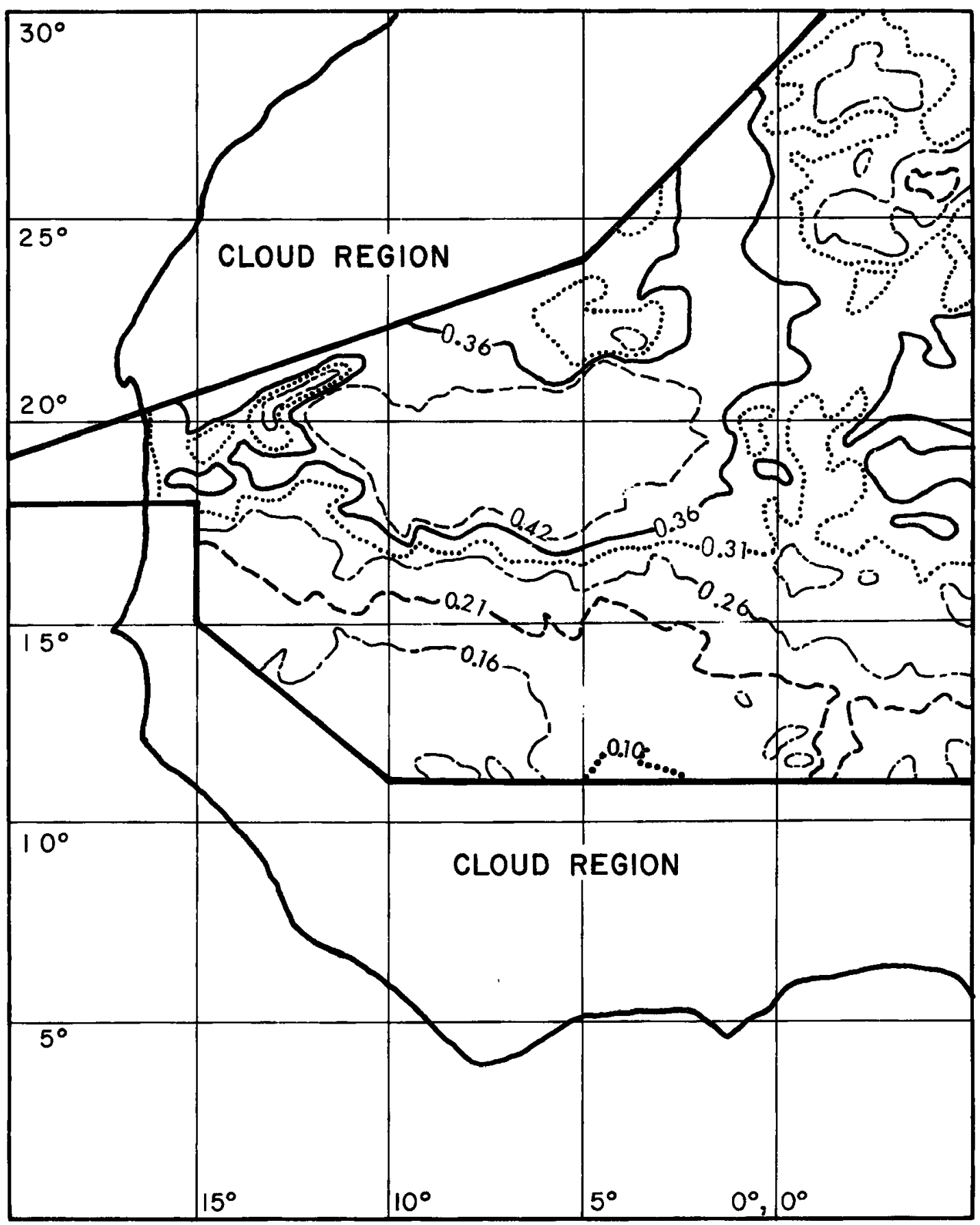

$\begin{array}{cccccc} & \alpha_{\text {SFC }} & \text { BRIGHTNESS } & & & \\ \cdots & 0.42 & 142 & --- & 0.21 & 98 \\ \cdots & 0.36 & 131 & -- & 0.16 & 84 \\ \cdots \cdots \cdots \cdots \cdots & 0.31 & 121 & \ldots . \cdots \cdots & 0.10 & 66 \\ -\cdots \cdots \cdots & 0.26 & 110 & & & \end{array}$

Figure 15. Surface albedo analysis for $1200 \mathrm{z}$ on September 20, 1974. 




Figure 16. Visible photograph from SMS-1 satellite at $1200 z$ on September 20, 1974. 
The southern limit of the bright sand region $\left(\alpha_{S F C}=.42\right)$ does not seem to be affected by the onset of the wet season, so the gradient from south co rorth appears to strengthen.

The seasonality of the surface albedo may be studied by following the novenent of the contours from Jury to September along the $10^{\circ} \mathrm{W}$ longitude zone. As was mentioned above, the .42 contour shows littie movement over the 80 day interval, remaining at a mean location of $17.5^{\circ} \mathrm{N}$. However, the .25 contour shifts from its mean July position of $15^{\circ} \mathrm{N}$ to a mean september position of $16.5^{\circ} \mathrm{N}$. The .21 contour shifts from $14^{\circ} \mathrm{N}$ to $15.5^{\circ} \mathrm{N}$ during the study period.

The change of albedo across the $15^{\circ} \mathrm{N}$ latitude zone of .25 to .19 represents a relative 25 percent decrease from July to September due to the changes in the surface characteristics. The following table summarizes the relative changes abserved at other latitudes along the $10^{\circ} \mathrm{W}$ zone.

\begin{tabular}{cccc} 
Lat. (oN) & $\begin{array}{c}a_{\text {SFC }} \\
\text { JuIy }\end{array}$ & $\begin{array}{c}\alpha_{\text {SFC }} \\
\text { Sept. }\end{array}$ & $\begin{array}{c}\text { Relative } \\
\text { percentage } \\
\text { change }\end{array}$ \\
\hline 12 & .75 & .15 & 0 \\
14 & .19 & .16 & 15 \\
15 & .25 & .19 & 25 \\
16 & .30 & .23 & 25 \\
17 & .36 & .34 & 5 \\
13 & .42 & .42 & 0 \\
\hline
\end{tabular}

Table 8 . Sumary of the seasonal change in surface albedo $\left(\alpha_{\text {SFC }}\right)$ along $10^{\circ} \mathrm{W}$ longitude.

The reason that the region aiong $13^{\circ} \mathrm{N}$ shows no apparent change in albedo, in seeming contradiction to the findings of Figure 8 , is that 
by July, $13^{\circ} \mathrm{N}$ is already well into the wet season, and any seasonality in albedo would not show up in the present study.

The analysis of Augusi 10 (Figure 13 ) does not seem to support the smooth transition of the albedo gradient from July to September. The reason for this is found in an analysis of the corresponding infrared (IR) brightness values which suggests the presence of some sub-grid scale cloudiness between $10^{\circ} \mathrm{W}$ and $15^{\circ} \mathrm{W}$. This would bias the visible brightness count toward higher values and result in the inference of surface albedos that are too large. The results of the analysis on August 10 point out the need for a proper assessment of the atmospheric characteristics before the inference technique is used.

A change in the araa within each surface class is evident by a comparison t the maps of July 2 and September 20. As a peans of quantifying this change, a pianimeter analysis was performed on the area bounded by $15^{\circ} \mathrm{N}, 20^{\circ} \mathrm{N}, 15^{\circ} \mathrm{W}$, and $5^{\circ} \mathrm{W}$. This rectangular area was cloud-free on both of these days, whereas August 10 showed some cloud contaminatich. On this basis, August 10 was eltminated from the area comparison. The following table sumarizes this analysis.

\begin{tabular}{|c|c|c|c|}
\hline \multirow{2}{*}{$\begin{array}{c}\text { Surface } \\
\text { Class }\end{array}$} & \multirow{2}{*}{$\begin{array}{l}\alpha_{\text {SFC }} \\
\text { Range }\end{array}$} & \multicolumn{2}{|c|}{ Percent of Tota? Area } \\
\hline & & JuTy 2 & September 20 \\
\hline $\begin{array}{l}7 \\
6 \\
5 \\
4 \\
3 \\
2 \\
1 \\
0\end{array}$ & $\begin{array}{l}>.42 \\
.36-.42 \\
.37-.36 \\
.26-.37 \\
.21-.26 \\
.16-.21 \\
.70-.76 \\
<.10\end{array}$ & $\begin{array}{r}30 \\
24 \\
24 \\
17 \\
4 \\
0 \\
0 \\
0\end{array}$ & $\begin{array}{r}29 \\
13 \\
15 \\
14 \\
20 \\
9 \\
0 \\
0\end{array}$ \\
\hline
\end{tabular}

Tabie 9. Percentage of the total area attributable to each surface class. 
Table 8 shows several significant differences between JuTy 2 and September 20. Again, the indication is that the bright sand region (class 7) is nearly unaffected by the seasonal variation of moisture. Thirty percent of the area fell into class 7 in july. In September tris area was 29 percent, representing a decrease of only 3 percent in ciass 7 surface area. In comparison, class 6 covered 24 percent of the area on suly 2, but by september 20, this area had been decreased by 46 percent by the increase in moisture and the development of surface vegetation. On July 2 cnly 5 percent of the area was class 3 . In Septenber, 20 percent was categorized as class 3.

Raschke et â. (1973) and Vonder Haar and collaborators (1974) have raported sateli ite observations of planetary albedo both globally and for continentâ? Africa. The "cloud-free" albedo patterns one infers from their results generally resembles the surface albedo maps shown in Figures 77,13 and 75 . The principal difference between the satellite data reported by the aforementioned authors and this study is that we show surface albedo inferred from satellite measurements while the previous studies have presented planetary albedo values. 


\subsection{CONCLUSIONS}

A technique has been successfuily developed that systematically accounts for the radiative effects of the atmosphere in measurements of the earth-atmosphere system reflectivity, and allows for remote measurements of the surface reflectivity from satellite radiance data. The albedo inference technique relies upon the energy conserving relationship between the bulk radiative properties in a mode? of the atmosphere that is bounded at the bottom by a partially reflecting, homogeneous surface. In this type of mode?, all of the incident solar energy is either reflected or absorbed by the earth-atmosphere system. The application of the technique is limited to atmospheric and solar geometry conditions writch are similar to those used in the vechniaue development.

The application of the technique on July 2, 1974 and Sertertoer 20, 1974 during the GATE showed that significant changes in the magnitude and gradient of the surface albedo do occur over northwestem Africa on a seasonal basis. A change in albedo from 25 to 19 percent, representing a elative 25 percent decrease, was measured at about 1 E $^{\circ}$ during the 80 day interval. Relative changes of 15 and 5 percent were found to occlir at $14^{\circ} \mathrm{N}$ and $17^{\circ} \mathrm{N}$, respectiveiy. Norich of $18^{\circ} 11$, changes of from 0 to percent were measured.

The deve:opment of the Surface Classification System allowed for a study of the changes in the physical nature of the various types of terrain in northwestern Africa. Surface types observed during the measurement of the surface albedo were classified according to vegetation type ard areal coverage, with each class corresponding to a specific albeco range. Surface class 7 , which corresponds to a desert 
surface having iess than 10 percent scrub vegetation, includes albedo values greater then 42 percent. Within class 7 are portions of the Sahara desert where alsedo values of 50 percent were measured.

Class 3 , the dminant class at $15^{\circ} \mathrm{N}$ during July, has an albedo range of $2 \%$ to 26 percent and includes an even mixture of vegetation and jight soins. however, with the onset of the wet season, the dominant class at the laticude changed to a class 2 , with a lower range of abedos (76 to 23 percent) and representing a terrain of mostly dark vegeteston and oniy 30 percent soils. The development of this classiffcation system aned for further analys is of the changes in terrain types $3 t$ ther regions of northwestern Africa.

An analysis of the area inc?uded within each surface class showed that large changes th the class sizes do occur in the GATE region. Class $6\left(c_{s p 0}=.35\right.$ to 42$)$, which comprised 24 percent of the area analyzed or $y \hat{z}$, was reduced to 13 percent of the area by September 20. Class 3 ape $=.23$ to .26$)$ increased from 4 percent to 20 percent of the sota: area. ny mon changes in area were found in the very low and very hign aloedo regions.

These sosone chenges in the surface albedo may be directly related to the Huctuations in the availability of moisture for precipitation during the owrse a year. This relationship is not completely undersood and he thus become an area of concern in recent general sincuation models. Carney (1975) has proposed a 40 percent decrease in the precigttation not th of $18^{\circ} \mathrm{N}$ due to an increase in the sumace albeco from, 74 to .35 north of this latitude. The results shown in the preste stucy suggest that the Sahara region north of $18^{\circ} \mathrm{N}$ is a compangryely steb: regon with respect to large changes in albedo. 
However, the smaller scale variations that are measured over this region affect a very large area and, thus, may be very significant due to the large area involved. South of $18^{\circ} \mathrm{N}$, larger scale changes are more common. It is hoped that the albedo information made available in this study will help investigators in gaining a better understanding of the earth-atmosphere interactions that occur in this area. 


\section{REFERENCES}

Albrecht, B.A., and S.K. Cox, 1976: Radiation data reduction procedures for sabre ther, $C-130$, and DC-6 aircraft during the GARP Atlantic Tropicai Experiment. Atmos. Sci. Paper No. 244, Colorado State University, Fort Collins, Co.

Aspliden, C.i. and D. Adefo aiu, 7976: The mean troposphere of west Arrica. J. Aopl. Meteor. 7, pp. $705-716$.

Brennan, B., and h. Bendeen, 7970: Anisotropic reflectance characteristics of natural earih surfaces. Appl. Optics, 9, pp. 405-412.

Budyko, M.I., 1969: The effect of solar radiation variations on the climate of the expth. Te Jus. 21, pp. 671-679.

Carison, T.N., 197. Comptation of solar radiation measurements made on Sal, Cape lende duming GATE. U.S. NOAA GATE Office, Rockville, Maryand, NSF Grant GHE-B379.

Charney, J.6. 9075: Wnamtes of doserts and drought in the Sahe1. Quart. U. Ro, Meteor. Soc. 101 , pp. 193-202.

Coulson, K.L. an. A. Pegnoids. $797 \%$ Spectral reflectance of natural surfaces. App Aeteor. 2 . pp. 1285-1295.

Cox, S.K., 797: Reining Qrodband Shortwave Irradiance Measurements to Raditive onotios of the Atmosphere. 2nd Conference on Atmosphemic sadicton Arlington, Virginia, Coliection of Abstracts. pp. 235-240.

Kondratyey, K.Ya., and Gsociates, 1976: Aerosol in the GATE area and its radtative probetibs. Atnos. Sci. Paper No. 247, Colorado State universtr. Gro colpins, Co.

Kriebel, K.T. F.74: The spectral reflectance of a vegetated surface. contrib. to chos. Prysics, 47 , pp. 14-44.

London 3. and $T$. Sesemon: 4 : Radiative energy budget of the atrosphere. Space peseanch; 11. pp. 639-649.

Otteman, J. p97: Earing Mich-albedo soils by overgrazing: A hypothesized desentrices on mechanism. Science, 186, pp. 531-533.

Panofsky. H. and a. Bn. Bner, 1958: Some Applications of Statistics to Meteorology. Dennsylyanta State University, University Park, PA.

Raschke, E. T.H. Ooncer Hazr, W.R. Bandeen and M. Pasternak, 1973: The wnua? Rodiation Salance of the Earth-Atmosphere System During 1969-70 Thor Mintus 3 Measurements. J. Atmos. Sci., 30, pp. 341-364.

Robinson, M., 7965: Soler Ratiation. Elsevier Publishing Co., Ansteron, London, and Nen Vonk. 


\section{REFERENCES - Continued}

Sellers, W. D., 1965: Physical Climatology. The University of Chicago Press, Chicago and London.

Smith, E. A., and T. H. Vonder Haar, 1976: Hourly Synchronous Meteorological Satellite-1 (SMS-1) data collected during the GARP Atlantic Tropical Experiment (GATE), Earth located, Edited data set. Atmos. Sci. Paper, Colorado State University, Fort Colitins, Co.

Vonder Haar, T. H., and K. J. Hanson, 1969: Absorption of solar radiation in tropical regions. J. Atmos. Sci., 26, pp. 652-655.

Vonder Haar, T. H., and collaborators, 1974: Radiation Measurements from Polar and Geosynchronous Satellites. Annual Report for NASA, 9 pages. 


\section{APPENDIX}

\section{CSAS -243 AuguSt 37,1974}

MISSION OBJECTIVE

The objective of CSAS - 243 was to sample a wide range of surface albedo over ocean surfaces, coastal swamps, dense forests, and mixed grass?ands.

\section{METEOROLOGTCAI COROTTIONS}

Meteorologicai conditions involved scattered cumulus and high cirrus over the oceans, increasing cumulus and scattered cumulus-congestus over the coasta? regions, and scattered trade cumulus over the inland regions. Trade cumulus tecreased in size and areal density over northern parts of the route with iarger cumulus again dominating the coastal regions. No dust layer was evident. The sea surface was unusually calm during the mission period.

\section{PRELIMINARY RESULTS}

Measurec aliedo vaiues were .04 over the calm sea surface, .09 over coastal swamps, .15 over dense forests, and .29 over mixed grasslands. All aircraft systems and measurement systems functioned properly. The mission was considered successfu?.

IRRADIANCE TEST CRITERIA

$$
\begin{aligned}
& \text { Hi }{ }_{\text {TOP }}=\text { seascratily adjusted Solar Constant } \\
& H_{\text {MnV }}=.90 \mathrm{H} \psi_{700} \cos \theta
\end{aligned}
$$

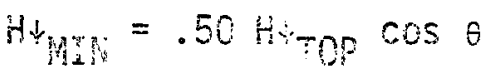

$$
\begin{aligned}
& H \text { HWN }=.64 H_{M M}
\end{aligned}
$$




\begin{tabular}{|c|c|c|c|c|c|c|c|c|}
\hline \multirow[b]{2}{*}{ TIME } & \multirow[b]{2}{*}{ LOCATION } & \multicolumn{2}{|c|}{${ }^{H \leftarrow} S F C$} & \multicolumn{2}{|c|}{${ }^{H+}$ SFC } & \multicolumn{2}{|c|}{${ }^{\alpha} S F C$} & \multirow{2}{*}{$\begin{array}{c}\text { SFC } \\
\text { CLASS }\end{array}$} \\
\hline & & MEAN & $\sigma$ & MEAN & $\sigma$ & MEAN & $\sigma$ & \\
\hline $13: 2046$ & $14.03^{\circ} \mathrm{N}, 16.85^{\circ} \mathrm{W}$ & 1044.3 & 134.4 & 35.4 & 8.1 & .03 & .005 & 0 \\
\hline $13: 2527$ & $14.03^{\circ} \mathrm{N}, 16.51^{\circ} \mathrm{W}$ & 1081.3 & 108.0 & 128.7 & 46.8 & .12 & .004 & 1 \\
\hline $13: 2956$ & $14.03^{\circ} \mathrm{N}, 16.18^{\circ} \mathrm{W}$ & 1034.3 & 154.4 & 55.8 & 25.0 & .15 & .017 & 1 \\
\hline $13: 3431$ & $14.03^{\circ} \mathrm{N}, 15.83^{\circ} \mathrm{W}$ & 1076.7 & 134.7 & 174.4 & 24.2 & .16 & .014 & 1 \\
\hline $13: 3906$ & $14.03^{\circ} \mathrm{N}, 15.51^{\circ} \mathrm{W}$ & 947.1 & 149.8 & 745.7 & 27.0 & .15 & $.07 !$ & 1 \\
\hline $13: 4341$ & $14.03^{\circ} \mathrm{N}, 15.18^{\circ} \mathrm{W}$ & 1068.7 & 80.4 & 157.0 & 11.8 & .15 & .009 & $\overline{1}$ \\
\hline $13: 4816$ & $14.03^{\circ} \mathrm{N}, 14.83^{\circ} \mathrm{W}$ & 1055.4 & 131.0 & 159.7 & 20.5 & .15 & .014 & $\bar{\tau}$ \\
\hline $13: 5251$ & $14.03^{\circ} \mathrm{N}, 14.57^{\circ} \mathrm{W}$ & 1068.0 & 113.2 & 157.2 & 15.2 & .15 & .011 & 1 \\
\hline $13: 5726$ & $14.03^{\circ} \mathrm{N}, 74.76^{\circ} \mathrm{W}$ & 1048.8 & 151.3 & 157.3 & 23.7 & .75 & .074 & $\mathfrak{i}$ \\
\hline $74: 0201$ & $14.06^{\circ} \mathrm{N}, 13.99^{\circ} \mathrm{W}$ & 1024.8 & 716.6 & 159.9 & 20.2 & .16 & .015 & $i$ \\
\hline $14: 0636$ & $14.50^{\circ} \mathrm{N}, 13.80^{\circ} \mathrm{W}$ & 1030.7 & 171.5 & 155.8 & 16.8 & .75 & .014 & 7 \\
\hline $74: 1711$ & $14.81^{\circ} \mathrm{N}, 13.67^{\circ} \mathrm{W}$ & 1010.7 & 117.9 & 158.6 & 22.0 & .16 & .017 & $i$ \\
\hline $14: 1546$ & $15.12^{\circ} \mathrm{N}, 13.54^{\circ} \mathrm{W}$ & 975.9 & 115.2 & 148.4 & 20.1 & .15 & .018 & 2 \\
\hline $14: 2021$ & $15.42^{\circ} \mathrm{N}, 13.41^{\circ} \mathrm{W}$ & 980.6 & 97.5 & 759.7 & 20.7 & .76 & .020 & 3 \\
\hline $14: 2456$ & $15.73^{\circ} \mathrm{N}, 73.28^{\circ} \mathrm{W}$ & 971.9 & 87.3 & $221 . \varepsilon^{\prime}$ & $27 . ?$ & .22 & .027 & 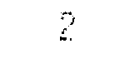 \\
\hline $14: 2937$ & $75.76^{\circ} \mathrm{N}, 73.59^{\circ} \mathrm{W}$ & 954.6 & 48.? & 768.6 & 73.5 & .18 & $.01 !$ & 2 \\
\hline $14: 3406$ & $15.75^{\circ} \mathrm{N}, 13.95^{\circ} \mathrm{W}$ & 913.8 & 57.3 & 767.8 & $77 . \because$ & .78 & .018 & 2 \\
\hline $14: 3841$ & $15.74^{\circ} \mathrm{N}, 14.37^{\circ} \mathrm{W}$ & 904.0 & 24.9 & 218.7 & 23.8 & .24 & .026 & 3 \\
\hline $14: 4316$ & $15.74^{\circ} \mathrm{N}, 74.67^{\circ} \mathrm{W}$ & 977.8 & 68.7 & 785.8 & 8.2 & .20 & .076 & 2 \\
\hline $14: 4751$ & $15.73^{\circ} \mathrm{N}, 15.03^{\circ} \mathrm{W}$ & 930.5 & 108.0 & 212.0 & 34.0 & .23 & .025 & 3 \\
\hline $14: 5226$ & $15.72^{\circ} \mathrm{N}, 15.38^{\circ} \mathrm{W}$ & 926.4 & 108.5 & 191.8 & 27.6 & .21 & .022 & 3 \\
\hline $14: 5701$ & $15.77^{\circ} \mathrm{N}, 15.75^{\circ} \mathrm{W}$ & 926.9 & 90.3 & $166 .:$ & 23.9 & .18 & .020 & 2 \\
\hline $75: 0136$ & $15.70^{\circ} \mathrm{N}, 16.77^{\circ} \mathrm{W}$ & 941.6 & 87.8 & 232.5 & 39.9 & .25 & .035 & 3 \\
\hline $15: 0611$ & $15.69^{\circ} \mathrm{N}, 76.47^{\circ} \mathrm{W}$ & 886.4 & 113.8 & 233.6 & 44.6 & .26 & .044 & 4 \\
\hline $75: 1046$ & $15.69^{\circ} \mathrm{N}, 16.83^{\circ} \mathrm{W}$ & 860.6 & 4.6 & 38.7 & 7.2 & .04 & .001 & 0 \\
\hline
\end{tabular}

Table A1. $20 \mathrm{~nm}$ averages for CSAS - 243. AT1 irradiance means and standard deviations are $\mathrm{Wm}^{-2}$. Time and location are for the midpoint of the $20 \mathrm{~nm}$ segments. 
Maximum measured aibedo $\quad-.35015: 0915 \mathrm{Z} ; 15.69^{\circ} \mathrm{N}, 16.70^{\circ} \mathrm{W}$

Minimum measured albedo $\quad-.07$ o $13: 2500 \mathrm{Z} ; 14.03^{\circ} \mathrm{N}, 16.54^{\circ} \mathrm{W}$

Sea surface measured albedo - .04 13:2000Z; $14.03^{\circ} \mathrm{N}, 16.91^{\circ} \mathrm{W}$

Sea surface measured albedo -.04 o $15: 1200 \mathrm{Z} ; 15.68^{\circ} \mathrm{N}, 16.93^{\circ} \mathrm{W}$

CSAS - 247 Septemiber 4,1974

MISSION OBJECTIVE

The objective of CSAS - 247 was primarily to sample the surface albedo over a uniform desert surface during a period of low $\left(\simeq 20^{\circ}\right)$ solar zenith angie, and secondartiy, to measure the total-sky shortwave irradiance at an altitude of $12.5 \mathrm{~km}$, and to compare these measurements with the calonjations of the Solar Constant.

METEOROLOGICAL COMUTTIONS

Meteorological conditions involved extensive cumulus-congestus and cirrus during the flight to the test area. On the periphery of the desert the cumulus dissipated, and only scattered cirrus was evident. During the high-level shortwave measurements, no clouds were visible and the sky was obscured. The top of the Saharan dust layer became evident at $5.5 \mathrm{~km}$. During the CSAS low-level flight, no clouds were observed, but the prasence of the dust was obvious in the visibility. One cumpionimbus (Cb) was noted at the end of the low-level flight. The retum Tight to Dakar was again into scattered cumulus-congestus and simes.

\section{PRELIMINARY RESULTS}

Measured albedo yalues were .48 over the most uniform sand surface and .40 cer an uneven sand surface with scattered vegetation. Highlevel shortave irmadiance measurements indicated a projected local 
noon Solar Constant extinction of 5 percent, with 2 percent attributable to the pressure weighted Rayleigh scattering, 2 percent to shortwave absorption by carbon dioxide, and 1 percent to shortwave absorption by ozone. A11 aircraft systems and measurement equipment functioned properly. The mission was considered successfu?.

IRRADIANCE TEST CRITERIA

$$
\begin{aligned}
& H_{\text {TOP }}=\text { seasonal1y adjusted Solar Constant } \\
& H_{\text {MAX }}=.90 \mathrm{H}_{\text {TOP }} \cos \theta \\
& H_{\text {MIN }}=.60 \mathrm{H}_{\text {TOP }} \cos \theta \\
& \mathrm{H}_{\text {MIN }}=.30 \mathrm{H} \downarrow_{\text {MIN }}
\end{aligned}
$$

$$
{ }^{H{ }_{S F C}} \quad{ }^{H \uparrow}{ }_{S F C} \quad{ }^{\alpha} S F C
$$

SFC

\begin{tabular}{ccccccccc} 
TIME & LOCATION & MEAN & $\sigma$ & MEAN & $\sigma$ & MEAN & $\sigma$ & CAAS \\
\hline $12: 1230$ & $18.25^{\circ} \mathrm{N}, 9.15^{\circ} \mathrm{W}$ & 1074.1 & 34.3 & 445.1 & 19.8 & .44 & .073 & 7 \\
$12: 1730$ & $17.11^{\circ} \mathrm{N}, 9.48^{\circ} \mathrm{W}$ & 1046.1 & 24.0 & 471.3 & 13.2 & .45 & .013 & 7 \\
$12: 2230$ & $17.95^{\circ} \mathrm{N}, 9.81^{\circ} \mathrm{W}$ & 1078.0 & 69.3 & 446.4 & 33.1 & .41 & .078 & 6 \\
$12: 2730$ & $17.79^{\circ} \mathrm{N}, 10.14^{\circ} \mathrm{W}$ & 1086.6 & 59.9 & 426.5 & 26.0 & .39 & .018 & 6 \\
\hline
\end{tabular}

Table Ai. $20 \mathrm{~nm}$ averages for CSAS-247. Al] irradiance mearis and standard deviations are $\mathrm{Wm}^{-2}$. Time and location are for the midpoint of the $20 \mathrm{~nm}$ segments.

Maximum measured albedo $-.48 @ 12: 1650 \mathrm{Z} ; 18.13^{\circ} \mathrm{N}, 9.43 \mathrm{~W}$

Minimum measured albedo $-.34 @ 12: 2745 \mathrm{Z} ; 17.78^{\circ} \mathrm{N}, 10.15^{\circ} \mathrm{W}$

CSAS - 248 September 5, 1974

MISSION OBJECTIVE

The objective of CSAS - 248 was to sample the surface albedo over a tropical rain forest. Coastal swamps were also sampled. Albedo measurements from this mission were obtained under a solid overcast. 
METEOROLOGICAL CONDITIONS

Metceorlogical conditions included low stratus and nimbostratus along the entire flight track. Visibility remained good throughout most of the mission. Scattered heavy showers, occurred along the flight track during the later stages of the mission. All surface types sampled were damp from recent rainfall.

PRELIMINGRY RESULTS

Measured albedo values were .04 over the mouth of the river, .09 over coasta swamos, and . 15 over the wet forests. Much of the data obtained during the rain showers were omitted. All aircraft systems and measurement equipment anctioned properiy. The mission was considered partiy successful due to the significant amount of cloudiness and ultimate rain showers.

\section{IRRAOIANCE TEST CRITERIA}

$$
\begin{aligned}
& H_{\text {TOP }}=\text { seasonally adjusted Solar Constant } \\
& H+M A X=.90 H+700 \cos \theta \\
& H_{\text {WIN }}=.50 H_{i}+00 \cos \theta \\
& H_{\text {MIN }}=.0444_{M I N} \\
& \text { Maximur measured atbedo - } 23 \text { o } 12: 0507 \mathrm{Z} ; 13.02^{\circ} \mathrm{N}, 12.19^{\circ} \mathrm{W} \\
& \text { Minimum measured albedo - .04 o } 11: 0940 \mathrm{Z} ; 12.62^{\circ} \mathrm{N}, 16.24^{\circ} \mathrm{W}
\end{aligned}
$$

\section{CSAS - 252 September 9, 7974}

\section{MISSICN CBUECTIVE}

The objectives of CSAS - 252 were similar to those of CSAS - 247, but the mission. was conclucted during a larger $\left(\approx 36^{\circ}\right)$ solar zenith angle. An attempt was made to sample the same desert surface and to study the albedo change wnder drfering solar parameters. 


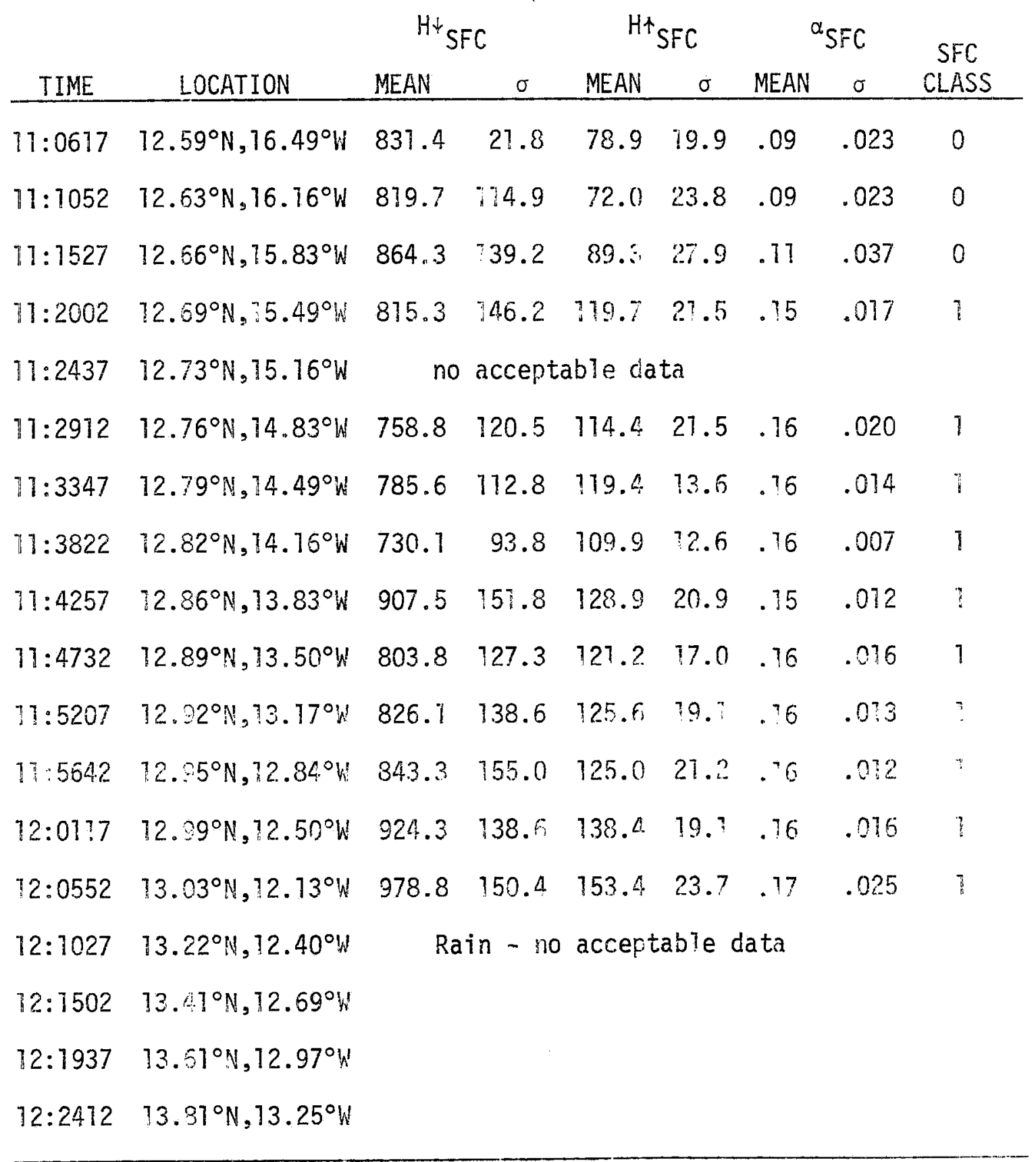

Table A3. $20 \mathrm{~nm}$ averages for CSAS - 248. A11 irradiance means and standard deviations are $\mathrm{Wm}^{-}$? . Time and location are for the midpoint of the $20 \mathrm{~nm}$ segments. 
METEOROLOGICAE COMOTTONS

Meteorological condtions were similar to those during CSAS - 247 with scattered cammus-congestus and high cirrus on the flight to the desert. Mo clouds were evident during the irradiance measurement perfods. The to of the Saharan dust layer was again apparent at $5.5 \mathrm{~km}$ diring the descent to the desert surface.

\section{PRELMINARY PESUT TS}

Measurec abedo watues were. 48 over the most uniform sand surface and 40 ore: ar meven sand surface with scattered vegetation. The comparison these dete with those from CSAS - 247 indicate no significant change of the swace abedo occurring within the range of solar zenith angles ano ${ }^{\circ}$ d $\left(20^{\circ}-40^{\circ}\right)$. All aircraft systems and measurement equipment fuctoned roperly. The mission was considered successfut.

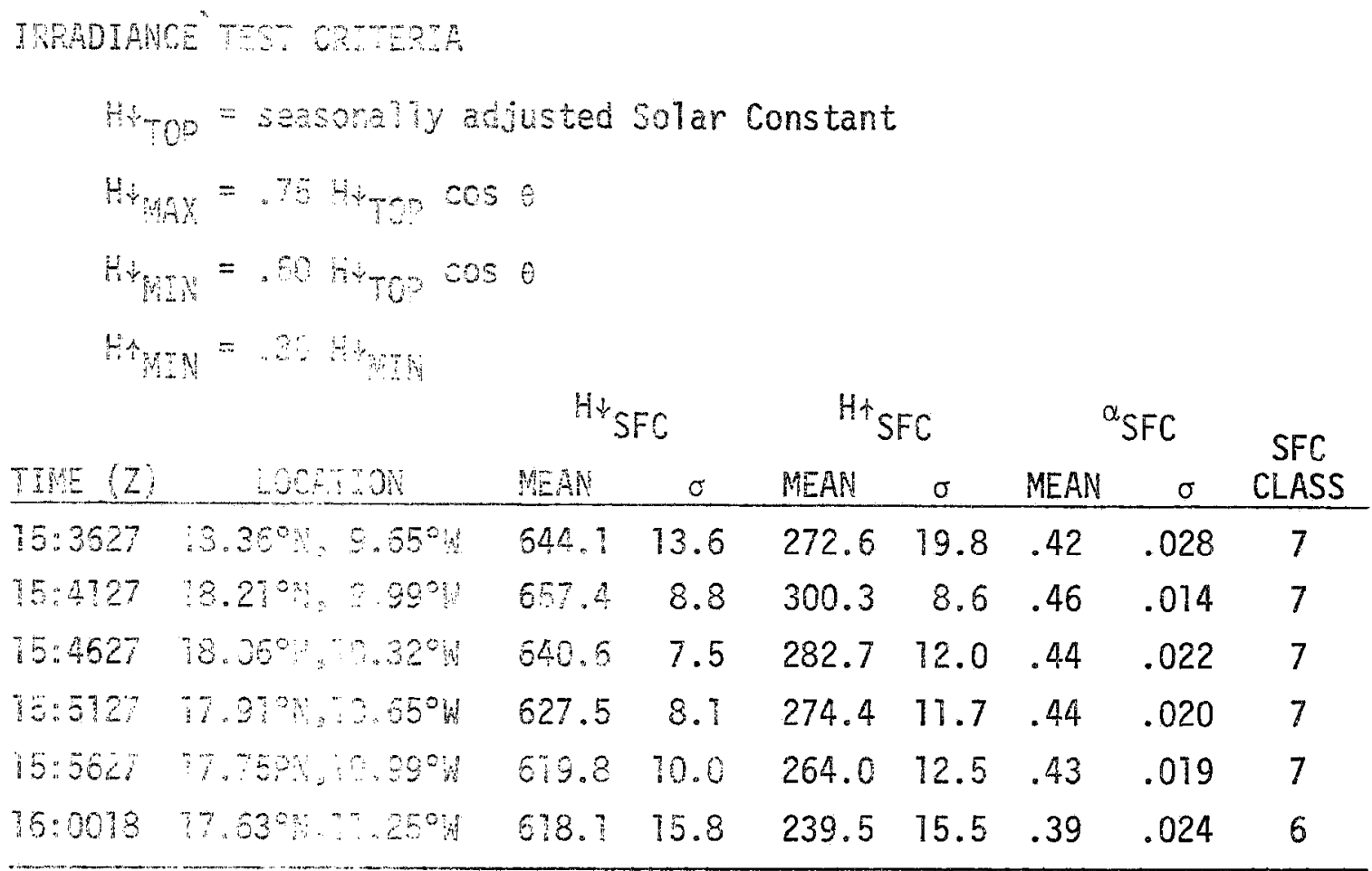

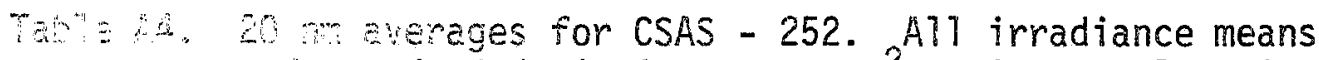

$$
\begin{aligned}
& \text { are standard deviations are } \mathrm{Wm}^{-2} \text {. Time and location } \\
& \text { ans the midpoint of the } 20 \mathrm{~nm} \text { segments. }
\end{aligned}
$$


Maximum measured albedo -.50 @ $14: 4552 \mathrm{Z} ; 18.08^{\circ} \mathrm{N}, 10.28^{\circ} \mathrm{W}$ Minimum measured albedo -.35 o $15: 5953 \mathrm{Z} ; 17.65^{\circ} \mathrm{N}, 11.22^{\circ} \mathrm{W}$ 